\title{
Patrón de urbanización, desarrollo agrario y tipos no tradicionales de empleo en la Microrregión Rosario, Argentina
}

\section{Urbanization pattern, agricultural development and non-traditional kinds of employment in Rosario micro-region, Argentina}

José Luis Pellegrini

ISABEL MARÍA RAPOSO*

\begin{abstract}
Non-agrarian rural and non-rural agrarian employment involves combinations of places of residence and workplaces which have become relatively frequent in Latin America. This article states that rural population with higher non-agrarian employment opportunities is that found around major urban areas, and that population centers are more attractive, as a residence place for the population with agrarian employment in the zone, to the extent they concentrate more heavily the total population. This paper corroborates the proposition on the base of the Rosario micro-region case study, in the Argentine Pampas.
\end{abstract}

Keywords: rural non-agrarian employment, non-rural agrarian employment, urbanization pattern, pampean region, Rosario.

\section{Resumen}

Los tipos de empleo rural no agrario y agrario no rural entrańan combinaciones de lugares de residencia y trabajo que se han vuelto relativamente frecuentes en Latinoamérica. En este artículo se argumenta que la población rural con mayores oportunidades de empleo no agrario es la que radica próxima a las grandes áreas urbanas, y que los centros poblados resultan tanto más atractivos como residencia de la población con empleo agrario de las zonas, cuanto más concentrada está en ellos la población total. Esta hipótesis se confirma mediante un estudio de caso en la microrregión Rosario, en la pampa argentina.

Palabras clave: empleo rural no agrario, empleo agrario no rural, patrón de urbanización, región pampeana, Rosario.

*Universidad Nacional de Rosario. Correos-e: jopelleg@fcecon.unr.edu.ar, raposoisabel@arnet. com.ar 


\section{Introducción}

Hace menos de dos décadas predominaba en el pensamiento económico y sociológico latinoamericano un paradigma tradicional que asociaba de manera casi indisoluble a los trabajadores residentes en zonas rurales con el empleo agrario, al punto que Klein (1992: 1) pudo decir, con referencia en los estudios sobre generación de empleo realizados en América Latina en esa época, que: “... cuando se habla de sectores no agrícolas... se refieren al área urbana y cuando se habla del sector rural se trata el tema de la agricultura”.

En la actualidad se acepta ampliamente que esa asociación no puede sostenerse, pero los usos están tan arraigados que las formas de empleo en las que se combinan lugar de residencia con sector de actividad, que en el pasado parecían inusuales, todavía no tienen un nombre verdaderamente propio o su denominación resulta ambigua. En efecto, en el uso académico la más estudiada de estas formas de ocupación es definida por exclusión y denominada con una negación: empleo rural no agrícola. Mientras que si se alude al empleo agropecuario urbano lo más probable es que sea asociado con la ocupación en la agricultura urbana y no con la ocupación de población urbana en actividades agropecuarias realizadas en el medio rural, por lo que a pesar de todo conviene recaer en la negación y hablar de empleo agrario no rural.

Numerosos estudios realizados en los últimos lustros, como los citados más adelante (secciones 1.2. y 1.3.), han puesto de relieve su importancia cuantitativa respecto al empleo rural no agrícola, en toda América Latina y, al menos en algunos países, el empleo agrario no rural. Esa nueva percepción, sin embargo, se basa por lo general en datos estadísticos de orden nacional o, menos frecuentemente, estadual o provincial, demasiado agregados en lo que se refiere a su alcance geográfico como para saber con precisión dónde se presentan esas combinaciones entre lugar de residencia y sector de actividad.

Poco después de la ronda de censos de 2000 se advirtió que a fines del siglo xx se habían alterado las tendencias en la distribución espacial de la población y se abrió una discusión acerca de si en América Latina, después de un largo periodo de urbanización concentrada en la o las mayores ciudades de cada país, están en curso procesos de contraurbanización o ruralización similares a los que aparecieron unas décadas antes en los países desarrollados de norteamérica y Europa. Las opiniones no son unánimes, pero algunos investigadores identificaron un fenómeno al que bautizaron con un oxímoron: desconcentración concentrada, con el que se da a entender que la población que deja las grandes ciudades cuyo 
atractivo disminuye, radica en sus alrededores y no en sitios más distantes (Rodríguez-Vignoli, 2008).

En algunos países, en Argentina en particular, los datos censales publicados no permiten saber si el crecimiento demográfico en esos alrededores se alimentó en realidad de la ciudad cercana, por lo que tiene sentido formular la hipótesis de la desconcentración concentrada en una forma que omita la referencia a la procedencia y se centre solamente en la modificación del patrón de distribución espacial de la población, esto es, dándole un sentido puramente distribucional.

$\mathrm{Al}$ tiempo que se estancaron las grandes ciudades y hasta decrecieron en términos absolutos algunas de las mayores metrópolis aumentó el dinamismo de las ciudades intermedias (Rodríguez-Vignoli, 2002) y, en Argentina al menos, también el de localidades de menor tamaño, desde los 5,000 habitantes según Lindenboim y Kennedy (2003; 2004). Y al igual que en otras partes, la antigua vitalidad de los grandes aglomerados urbanos de la región pampeana parece haberse trasladado a sus alrededores, donde Leveau (2009) encontró una tasa intercensal de aparición de nuevas localidades mayor que en el resto de la provincia a la que cada aglomerado pertenece.

Entonces surge casi naturalmente la pregunta acerca de si lo observado en materia de empleo se relaciona de alguna manera con el patrón de urbanización tanto en las zonas con características metropolitanas o periurbanas, como en la vitalidad de las ciudades pequeñas y los pueblos inmersos en el medio rural.

Bryden y Bollman (2000) y Bollman (2007), entre otros, enfatizan que la identificación tradicional entre rural y agrario ya no es válida en los países más industrializados, donde la población de las grandes ciudades emigra al campo sin dejar sus empleos urbanos para poder disfrutar del contacto con la naturaleza y de las mejoras en infraestructura, equipamiento y servicios (amenities) creadas por la población rural (Cavailhès et al., 2004; Champion, 2009). Pero no es seguro que ese fenómeno pueda asimilarse con lo observado en América Latina, donde al igual que en gran parte del mundo en vías de desarrollo, el medio rural no se destaca tanto por su atractivo hedónico como por la pobreza de gran parte de sus habitantes y, tal como lo afirman Pizzoli y Gong (2007), las áreas rurales todavía están asociadas con el agro y, por lo general, coinciden con las áreas agrarias.

Es indudable que la mayor parte del trabajo agrario directamente productivo se realiza en el campo, aunque no todos los trabajadores residan allí, y es probable que parte de la población rural con ocupaciones no agrarias se desempeñe en sitios urbanos, lo que significa que la conformación espacial de los mercados laborales es más compleja de lo que 
sugiere la dicotomía tradicional, que apareaba a priori lugar de residencia con sector de actividad. Es verosímil que las formas de empleo consideradas sean, cuantitativamente, poco significativas en relación con la ocupación total, pero indudablemente no lo son en relación con la magnitud de las poblaciones específicas para las cuales pueden presentarse como alternativas relevantes.

Por ese motivo no es indiferente la escala en que se aborde el estudio del fenómeno, ya que proporciones altas o bajas localmente significativas pueden quedar disueltas en los promedios generales y éstos, a su vez, pueden ser afectados por elevadas concentraciones en lugares específicos y no muy extensos. En virtud de la heterogeneidad espacial que suelen crear las grandes ciudades en sus alrededores parece imprescindible que, cualquiera que sea la escala elegida para el estudio de estos fenómenos, se adopten unidades de análisis espacial suficientemente pequeñas como para que sea posible comparar los alrededores de las grandes concentraciones urbanas con zonas rurales algo más alejadas, ya que las diferentes combinaciones posibles entre lugares de trabajo y de residencia pueden presentarse con distinta intensidad en unas u otras.

En la parte empírica de esta investigación se utilizan datos de origen censal suficientemente desagregados como para distinguir las áreas próximas de las distantes de una gran ciudad y su conurbano. Con un enfoque de estudio de caso, en este artículo se aborda el problema de la distribución espacial de los empleos rural no agrario y agrario no rural en una escala microrregional. El caso estudiado es el de la Microrregión Rosario, situada en el sur de la provincia de Santa Fe, en el núcleo agroexportador de la región pampeana argentina, la cual combina una intensa actividad agrícola con la existencia de un gran aglomerado urbano y una red de ciudades pequeñas y pueblos que cubre todo el territorio. La elección como estudio de caso responde a que esa combinación facilita la puesta a prueba de las hipótesis propuestas a continuación.

Entendiendo por rural a la población que reside fuera de los centros poblados (sección 3), en este artículo se argumenta que la población rural que tiene mayores oportunidades de empleo no agrario es la que se encuentra en los alrededores de las grandes áreas urbanas. También se sostiene que los centros poblados resultan tanto más atractivos, como lugar de residencia de la población con empleo agrario en sus alrededores, cuanto más concentrada tiende a estar la población total en tales centros. En consecuencia, se formulan las siguientes hipótesis para el caso estudiado: 1) el empleo rural no agrario tiende a concentrase en las proximidades del Aglomerado Gran Rosario; y 2) la proporción de empleo agrario no rural de cada distrito que contiene una ciudad o pueblo tiende a ser mayor cuanto más concentrada esté la población del distrito en 
esa localidad. En otras palabras, el empleo agrario de un distrito tiende a concentrarse espacialmente en su centro poblado y, en ese sentido, a ser no rural en función creciente del grado de urbanización. ${ }^{1}$

Para poner a prueba estas hipótesis, en la sección 1 de esta investigación se realizó un análisis estadístico y econométrico espacial que permitió corroborarlas; previamente, se hizo un recorrido sobre la literatura especializada en el tema; mientras que en las secciones 2 y 3 se discute la noción de ruralidad utilizada en América Latina y se propone una que se considera apropiada para la región pampeana argentina, en general, y para la zona estudiada, en particular. En la sección 4 se introduce el concepto de área económica local para luego, en la sección 5, describir la región bajo estudio y exponer el análisis estadístico y econométrico antes mencionado. Finalmente se presentan las reflexiones finales.

\section{Antecedentes conceptuales}

\subsection{Los conceptos rural y agrario en la literatura sobre el tema ${ }^{2}$}

En la reciente literatura latinoamericana especializada en el tema del empleo, los términos rural y urbano se utilizan para especificar el lugar de residencia de la población, mientras que los términos agrícola y no agrícola (y a veces agropecuario y no agropecuario) designan a la rama de actividad de la ocupación principal.

Así, en los trabajos citados en la próxima sección, la expresión empleo rural no agrícola (traducción de rural non-farm employment) designa la ocupación de la población rural en una rama de actividad diferente de la agricultura, en un sentido amplio que no abarca sólo ganadería sino también caza, silvicultura y, a veces, pesca. Con un significado análogo, otros autores como Weller (1997) así como Craviotti y Gerardi (2002) utilizan el término agropecuario, que en castellano resulta más apropiado y facilita la distinción de la agricultura en sentido estricto de las demás actividades con las que se la agrupa a los fines estadísticos, y que en la región pampeana argentina son casi exclusivamente ganaderas. En este artículo también se adopta el término agropecuario, al igual que agrario como sinónimo, ya que éste es utilizado por la legislación laboral argentina cuando se refiere al trabajo en el sector. ${ }^{3}$

${ }^{1}$ Debe distinguirse esta hipótesis de aquélla que sostiene que, dentro de la fuerza de trabajo de cada localidad, la proporción de población económicamente activa dedicada a actividades agrarias es una función decreciente del tamaño de la localidad, hipótesis que también es consistente con la evidencia empírica para Argentina (Castro y Reboratti, 2008).

${ }^{2}$ Esta sección y partes de la siguiente están basadas en Pellegrini (2008).

${ }^{3}$ Ley 22.248 de Trabajo Agrario. 
Con respecto al lugar de residencia, el concepto de ruralidad -comúnmente adoptado por el grupo de autores mencionado- es el que se emplea en las estadísticas oficiales de cada país, cuyos datos analizan que en Latinoamérica, en general, existe una distinción dicotómica entre rural y urbano a partir de un umbral cuantitativo o cualitativo situado en el nivel de los centros poblados pequeños. El criterio para fijar dicho umbral varía entre países: en algunos se tiene en cuenta la cantidad de habitantes, con límites de 1,000, 2,000 o 2,500; en otros, destacan otras características cualitativas como la condición de cabecera municipal, y finalmente, en otros, una combinación de características cuantitativas y cualitativas como la cantidad de habitantes con la condición de cabecera municipal o la existencia de servicios básicos (CEPAL-Celade, 2005; Matjasevic y Ruiz-Silva, 2013). La población dispersa y la residente en centros poblados que no alcanzan el umbral fijado se considera rural. Para las estadísticas argentinas publicadas por el Instituto Nacional de Estadística y Censos (INDEC) el límite es de 2,000 habitantes, sin otra condición, distinguiéndose entre población rural agrupada y dispersa según se encuentre en una localidad cuyo número de habitantes está por debajo de dicha cantidad o en campo abierto (INDEC, 2001).

\subsection{Empleo rural no agrario}

Según se reconoce generalmente en la literatura sobre el tema, la importancia del empleo rural no agrario (ERNA, por las siglas utilizadas en obras que se ocupan de esta materia) en Latinoamérica fue destacada por primera vez a comienzos de los años noventa por Klein (1992), quien después de analizar datos correspondientes a 18 países llegó a la conclusión de que como actividad principal había estado aumentando en las décadas anteriores, y que para fines de la década de 1980 ya daba cuenta de un tercio de la mano de obra ocupada en las áreas rurales.

En realidad no se trataba de un tema totalmente nuevo, porque el fenómeno descrito tiene cierta analogía con el que ya había sido observado en Estados Unidos en los ańos treinta (Jenkins y Robison, 1937) y que fue inicialmente denominado producción agropecuaria a tiempo parcial (part time farming) y, posteriormente, multiocupación o pluriactividad. Fue interpretado inicialmente como resultado de una práctica restringida a las franjas marginales e ineficientes del sector agropecuario, que se presentaba porque la necesidad de obtener ingresos para mantener los establecimientos en marcha obligaba a algunos miembros de las familias rurales a buscar empleo fuera de ellos (Craviotti, 1999).

Poco a poco se advirtió que se trataba de un comportamiento resultante de estrategias familiares de vida que no se encontraba solamente en 
segmentos marginales, sino que estaba más generalizado y se expandía a medida que la reducción de los costos de transporte abarataba el traslado de los trabajadores. En la actualidad afecta a la mayor parte de la agricultura familiar estadounidense, en la que una fracción importante de la población ocupada se dedica a ella como segunda carrera laboral y tiene su principal ocupación o fuente de ingresos en otro sector de actividad (Mishra et al., 2002).

También se observó que, con diferentes intensidades, el ERNA está presente en numerosos países del mundo, no se restringe a los hogares pobres y contribuye significativamente a conformar los ingresos de la población rural (Reardon et al., 2006). Debido al interés que este hecho despertó en los últimos lustros se generaron numerosas publicaciones respecto al tema, todas de considerable coherencia conceptual y referidas específicamente a los países de América Latina. Entre las contribuciones al respecto destacan los artículos publicados en un número especial de la revista World Development (Streeten, 2001) en las que se revela que la proporción de población rural ocupada fuera del sector agropecuario es muy importante, especialmente entre las mujeres, e internacionalmente muy variable (Berdegué et al., 2001).

En un estudio más reciente sobre 14 países (entre los que no se cuenta Argentina) se advierte que éstos comprenden $80 \%$ de la población rural latinoamericana, Köbrich y Dirven (2007) estiman con datos de encuestas de hogares realizadas en 2001 y 2002 que, en promedio, el ERNA representa 35\% de la población rural ocupada, variando entre 14 y $65 \%$, según el país. Aplicando una definición de ruralidad análoga a las de los autores citados y utilizando datos censales, en 2001 ese valor es de 51\% para Argentina.

Las investigaciones que dan lugar a la literatura mencionada tienen dos limitaciones que no pasaron inadvertidas para algunos de los mismos autores que las llevaron a cabo. La más evidente deriva de que los datos analizados son de nivel nacional o a lo sumo estadual o provincial, como en Ferreira y Lanjouw (2001) y Craviotti y Gerardi (2002), respectivamente, lo que impide conocer la distribución geográfica del ERNA dentro de cada jurisdicción y, en particular, la relación entre dicha distribución y la localización de las ciudades de diferente tamańo. Incluso en trabajos econométricos como los que se encuentran en el número de World Development (Streeten, 2001), así como en CEPAL (2003), cuando se procura captar de alguna manera la localización se hace mediante variables dicotómicas referidas a ciertas zonas consideradas diferenciadas (como áreas metropolitanas, departamentos o regiones), pero no mediante alguna medida específicamente espacial que represente la posición geográfica. 
Por lo tanto, no se modelan las relaciones espaciales, quedando en la oscuridad la influencia de éstas en la distribución de la variable estudiada dentro y fuera de dichas zonas. Por cierto, ésta es una limitación que no se encuentra solamente en la obra de los autores analizados, sino que se presenta también en otros intentos de incorporar, de alguna manera, la dimensión espacial en el análisis de los problemas rurales latinoamericanos, por ejemplo en algunos trabajos glosados por De Ferranti et al. (2005).

$\mathrm{Al}$ respecto, Dirven (2004) señala que un tema que merece mayor estudio es, precisamente, el de la localización y sostiene que la mayoría de los artículos que examinó

\footnotetext{
muestran también que, salvo escasas excepciones, el ERNA es más frecuente y más dinámico cerca de las zonas más densamente pobladas o que están bien conectadas con las ciudades (p. 65) [...] (y) parecen poner de manifiesto una asociación estrecha entre la localización y el tipo y dinamismo del ERNA, pero en general los autores no llegan a relacionar este aspecto con sus demás hallazgos, ni a señalar la localización como quizá el principal factor explicativo (p. 68, las cursivas son nuestras).
}

La otra limitación, tal vez algo más sutil pero estrechamente relacionada con la anterior, deriva de la definición de población rural, tanto porque es dicotómica como porque mezcla poblaciones agrupadas y dispersas. Köbrich y Dirven (2007) se centran en el primer aspecto y advierten que la utilización de un gradiente que permita distinguir diferentes grados de ruralidad en cada país podría llevar a conclusiones totalmente distintas a las obtenidas hasta el momento. Asimismo, señalan que las características personales de los trabajadores rurales son desiguales según estén ocupados en el sector agrario o no agrario y enfatizan que no existe evidencia de libre movilidad entre ambos sectores sino que, por el contrario, el segundo presenta fuertes barreras a la entrada. Sin embargo, se inclinan a atribuir las diferencias a la autoselección y no consideran la posibilidad de que dichas características se deban, al menos en parte, a que la población comprendida en la categoría de rural sea en realidad un agregado de dos o más poblaciones.

$\mathrm{Si}$, como es muy plausible, una cantidad relativamente grande de puestos de trabajo no agrarios ocupados por población rural se localiza en centros poblados, los trabajadores que residen en campo abierto puede tener mayores dificultades para acceder a ellos si su vivienda está distante, los medios de transporte son inadecuados o la exposición a las contingencias climáticas hacen insegura la concurrencia regular al lugar de trabajo. Así, es posible que la proporción de población rural ocupada en actividades no agrarias sea más alta entre los residentes de los centros 
poblados y a la inversa, que sea la población dispersa en las zonas de producción agraria la que se emplee mayoritariamente en ésta.

En la medida en que no se distingue a la población rural dispersa en campo abierto de la agrupada en localidades y, dentro de ésta, a la agrupada en localidades que difieren entre sí por su tamaño y situación geográfica, la definición de ruralidad utilizada puede agregar en su conceptualización a las poblaciones que son heterogéneas en lo que respecta a sus oportunidades de empleo, de modo que la división dicotómica entre rural y urbano sobre la base de los criterios usuales puede constituir un factor que abulta injustificadamente el ERNA al tiempo de juzgar su importancia económica y significado social.

El ERNA adquiere entidad como fuente alternativa de ingresos para la población local cuando la actividad agropecuaria predomina en áreas extensas desde las cuales las ciudades no son fácil ni rápidamente accesibles, así como en las regiones donde una parte importante de la población económicamente activa emigra estacionalmente por razones de trabajo agrario, pero no allí donde hay una relativa abundancia de puestos de trabajo en otras ramas de actividad y donde la ocupación en el sector agropecuario se presenta como una posibilidad más.

Aglomeraciones clasificadas como rurales, pero cuya población se acerca de los 2,000 a 2,500 habitantes y, aún más, según los países, pueden ser capaces, debido a su propia escala, de crear oportunidades de especialización productiva en la industria y los servicios privados así como de justificar el desarrollo de una burocracia gubernamental y generar establecimientos educativos, sanitarios, policiales, etc., con sus correspondientes demandas de trabajo en el sector terciario. Como aun recibiendo la calificación de rurales tienen el carácter de lugares de concentración de establecimiento de una multiplicidad de ramas, no puede sorprender que exista en ellos una proporción considerable de empleo no agrario.

Cabe señalar que el ERNA adquiere un significado por completo diferente en los lugares turísticos y en las inmediaciones de las grandes ciudades, en las que puede haber zonas con población dispersa o agrupada en localidades pequeñas pero totalmente integradas a la vida urbana de manera que su ruralidad no es mucho más que una ilusión estadística. Esa población seguramente tiene necesidades, particularmente de servicios, que crean oportunidades de empleo para otros grupos de personas que se benefician indirectamente de la cercanía con las ciudades y para las cuales la ocupación en el sector agropecuario puede ser una alternativa por completo irrelevante.

$\mathrm{Al}$ respecto debe decirse que se nota en la literatura consultada cierta incongruencia entre discurso teórico y propuestas de política económica, por un lado, y estudios estadísticos y econométricos, por el otro. Mientras 
el discurso y las propuestas se refieren a una población a la que se describe con características y con problemas que permitirían identificarla no sólo como rural, sino como campesina (y ocasionalmente se la nombra así, como en Dirven, 2006), los estudios empíricos cuantitativos, ateniéndose a las definiciones estadísticas, se ocupan de una población que en parte podría no tener relación directa alguna con la actividad agraria y ni siquiera con un tipo de vida que se pueda calificar de rural en un sentido significativo. Obviamente, la incidencia que pueda tener este último tipo de población puede variar en gran medida entre países y regiones, pero no puede asegurarse a priori que sea despreciable. ${ }^{4}$

\subsection{Empleo agrario no rural}

Cambiando el centro de atención de lo rural a lo agrario, la expresión empleo agrario no rural se utiliza aquí para designar a la ocupación en el sector agropecuario de población que no reside en zonas rurales. Como ya se dijo, se la define mediante una negación (cuando en principio pudo haberse utilizado la palabra urbano) para evitar la confusión con el empleo en la agricultura urbana, entendida como aquella que se practica dentro de las ciudades, en espacios intersticiales como patios de viviendas, lotes baldíos y terrenos públicos. Impulsada por algunos gobiernos locales y por el Estado nacional que en ocasiones llegó a exigir su práctica como contraprestación de subsidios a desocupados, este tipo de agricultura se volvió importante en Argentina después de la crisis de 2001-2002, siendo que antes estaba muy poco difundida en las ciudades pampeanas.

Mientras el empleo rural no agrario o fuera del establecimiento familiar, así como el empleo urbano en la agricultura urbana y periurbana son objeto de numerosos estudios en todo el mundo, el hecho de que una proporción importante de la población ocupada en las actividades agropecuarias que se realizan en el medio rural no sea rural, parece llamar la atención más en Argentina que en otras partes, al punto que en una extensa búsqueda bibliográfica sólo fue posible encontrar unas pocas menciones al respecto en la literatura internacional reciente en lenguas castellana e inglesa, entre las que destacan la trascripción de una conferencia de Lagos-Escobar (2008) cuyo campo de estudio fue principalmente Chile.

\footnotetext{
${ }^{4}$ Es cierto que puede haber, especialmente en los países andinos y centroamericanos que están entre los más estudiados por los autores que adoptan el enfoque comentado, regiones de bajo grado de desarrollo relativo donde la vida agraria predomine de tal manera que condicione a toda la población rural, inclusive a la de localidades pequeñas que tal vez se considere a sí misma tan campesina como la del campo abierto. Pero aun en esos casos parece imposible que la población rural de países enteros no comprenda cierto número de habitantes de zonas con economías más diversificadas.
} 
Algo parecido ocurre con un fenómeno relacionado: el de los viajes pendulares diarios por motivos de trabajo entre áreas rurales y urbanas, donde los estudios se han centrado en aquellos cuyos puestos de trabajo se encuentran en las ciudades. Aunque Schindegger y Krajasits 1997, citados por Harris et al., (2008) advirtieron hace tiempo que en algunos países de la Organización para la Cooperación y el Desarrollo Económico (OCDE) la dirección de los viajes pendulares diarios hacia lugares de trabajo localizados en el medio rural (definido de acuerdo con el criterio de esa organización, vide infra) son más numerosos que los que se hacen en sentido contrario, las investigaciones al respecto no abundan y menos aún las que específicamente se refieren a los puestos de trabajo agrarios, lo que sugiere que no es un tema que hasta el presente haya despertado interés.

Esta apreciación se ve reforzada por una observación que se refiere a un aspecto íntimamente vinculado: el del alojamiento. En su revisión de la literatura internacional sobre el problema de la vivienda de los trabajadores agrarios que residen fuera de las explotaciones (off farm housing) en zonas urbanas, realizada con el fin de buscar antecedentes para evaluar una experiencia en Sudáfrica, Hartwig y Marais (2005) encontraron pocos trabajos al respecto en lengua inglesa, concluyendo que se trata un asunto que en el mundo ha recibido una atención limitada.

No obstante, un tema relacionado con el empleo agrícola no rural fue abordado en varios estudios realizados en Estados Unidos, Canadá y Australia hace varias décadas (Ashby, 1941; Lier, 1971; Williams, 1970), en los que se analiza un fenómeno que recibiera varias denominaciones en inglés, entre ellas: non resident farming (Belcher, 1954). Sin embargo, estos trabajos no se referían en realidad al empleo agrario en general, sino que estaban motivados por un interés específico: el del desplazamiento de los titulares de las explotaciones (farmers) y sus familias a centros poblados; lo que para algunos investigadores, como Kollmorgen y Jenks (1958) entrañaba riesgo económico cuando los lugares de residencia y trabajo estaban alejados, y hasta cierta debilidad moral, según da a entender Belcher (1954).

En lo que se refiere a Argentina, varios autores enfatizaron que proporciones importantes de población ocupada en actividades agropecuarias son urbanas y residen no sólo en localidades pequeñas, sino también en ciudades cuyo promedio de habitantes es de 10,000 a 50,000 y más (Benencia y Quaranta, 2006; Raposo y Pellegrini, 2008). De acuerdo con Neiman y Bardomás (2001) la participación de la población urbana (definida de acuerdo con el criterio oficial) en el empleo agrario crece al menos desde hace tres décadas: entre 1980 y 1991 se observó un crecimiento de 21.2 a $29.3 \%$ en el promedio nacional. Según la estimación de los presentes autores, dicha participación llega a 36.5\% en 2001. 
Aunque el estudio de lo ocurrido con anterioridad a la década de 1980 está limitado por la disponibilidad de información publicada, es indudable que el proceso comenzó mucho antes y ya en una fecha tan temprana como 1864. W. Perkins (citado por Gallo, 2004), presidente de una compañía dedicada la colonización y fraccionamiento de tierras, notó que los agricultores provenientes de Europa preferían vivir en el pueblo y no en las chacras. Como muchos de ellos no habían sido campesinos en sus países de origen, es posible que algunos quisieran conservar sus costumbres urbanas y que otros, desconociendo por completo el ambiente al cual llegaban, tuvieran expectativas de reproducir, en un lugar donde la densidad demográfica y las condiciones agronómicas lo hacían extremadamente difícil, la práctica ancestral de vivir en aldeas y desplazarse diariamente a las tierras de labor.

Sea porque la preferencia por vivir en pueblos y ciudades más que en el campo se transmitió a las siguientes generaciones, sea porque Argentina se presenta como un caso flagrante de sesgo urbano en donde los recursos se concentran desproporcionadamente en las grandes ciudades (tanto más cuanto mayor sea su importancia política), la propensión de la población ocupada en el sector agropecuario a residir en centros poblados ha persistido a través del tiempo.

Así, Gorenstein et al. (2007) observan que los productores agropecuarios de la provincia de Buenos Aires prefieren vivir en las cabeceras de los partidos, ${ }^{5}$ que por lo general son ciudades no muy grandes pero de importancia local. Murmis y Feldman (2006) señalan un fenómeno análogo, pero extendido a otras categorías ocupacionales en un pueblo pequeño de la misma provincia, llamando la atención sobre la independencia del lugar de residencia de esos trabajadores respecto de las explotaciones donde se emplean. En el extremo opuesto de la jerarquía urbana, la ciudad de Buenos Aires y su conurbano son, según mencionan Neiman et al. (2006), lugares de residencia de productores agropecuarios de un partido no muy alejado de ese gran aglomerado urbano.

Asimismo, en un estudio sobre características de una muestra de productores agropecuarios del sur de la provincia de Santa Fe, Gras (2004) encuentra que $83 \%$ de los mismos y sus familias vive en lo que llama centros urbanos. Con referencia al mismo contexto geográfico, Albanesi y Propersi (2006) y Cloquell (2007) identifican al cambio de residencia

\footnotetext{
${ }^{5}$ La provincia de Buenos Aires se divide en partidos, jurisdicciones de gobierno municipal que por lo general cuentan con una localidad principal (donde está la sede gubernamental) y algunas otras de menor tamańo. Las demás provincias se dividen en departamentos, cuya relación con el régimen municipal varía entre una y otra, pero que al igual que los partidos son divisiones políticoelectorales que se utilizan como unidades espaciales de agregación de datos estadísticos.
} 
(de rural a urbana) como uno de los factores que más afectaron en años recientes el modo de vida de las familias chacareras.

Si bien puede pensarse que la desruralización del empleo agrario en Argentina ha llamado la atención más que en otras partes por tratarse de uno de los países con mayor grado de urbanización en América Latina que a la vez tiene una agricultura de importancia mundial, debe mencionarse que el fenómeno también se observa en las regiones argentinas de menor desarrollo relativo donde, como señalan Neiman y Bardomás (2001), el peso del empleo agrario puede equipararse a los promedios nacionales de países como Colombia, México o Brasil, aunque las razones no tienen porque ser las mismas que en la región pampeana.

En relación con esta última, las explicaciones que se han ofrecido para dicho fenómeno han sido varias, por lo general centradas en los avances tecnológicos que reducen la demanda de mano de obra y la vuelven más exigente en cuanto a calificaciones; la concentración de las tareas agrícolas en periodos cada vez más breves con aumento de los tiempos muertos, la retracción de la explotación familiar (Gras, 2013), el avance del contratismo ${ }^{6}$ que tiende a reclutar personal temporario entre la población urbana y, particularmente, la incorporación de maquinaria con creciente capacidad de labor (Urcola, 2013). Todos estos factores están presentes desde hace tiempo, pero es indudable que fueron potenciados por la generalización de la siembra directa en el cultivo de cereales y oleaginosas y el uso de semillas transgénicas como en el caso de la soja. ${ }^{7}$

La siembra directa se desarrolló inicialmente en Estados Unidos con fines conservacionistas y fue adoptada poco a poco en Argentina, Brasil y Paraguay a partir de los años ochenta, pero su aplicación se generalizó por sus ventajas de costos a mediados de la década de 1990 cuando se liberaron al mercado las semillas transgénicas resistentes al glifosato, un herbicida total. Actualmente se está expandiendo a otros países como Bolivia, Uruguay y Venezuela. Con esta técnica el cultivo se implanta y protege sin necesidad de roturación ni labores culturales anteriores o

\footnotetext{
${ }^{6}$ La expresión contratismo denomina a la práctica de delegar a terceros llamados contratistas, la realización de labores agrícolas bajo la forma de prestación de servicios agropecuarios pero también entregando la tierra en arrendamiento o aparcería sin que el inquilino se residencie en el predio, en cuyo caso la denominación se aplica por extensión. El prestador de servicios cobra por labor realizada mientras que el arrendatario o aparcero que se hace cargo total o parcialmente del riesgo agrícola se denomina productor agropecuario, al igual que el propietario que se hace cargo de la explotación (Lódola Agustín et al., 2005). Pero es muy común que las mismas personas o sociedades que explotan por su cuenta tierra propia y alquilada presten también servicios a terceros, no obstante lo cual existen prestadores puros que por lo general son empresas pertenecientes a antiguos productores o sus hijos, ingenieros agrónomos, comerciantes de agroquímicos, etcétera.

${ }^{7}$ Si bien el uso de estas técnicas se generalizó e intensificó en Argentina después de la fecha a la que se refiere esta investigación, en ese momento ya estaban plenamente presentes en la región estudiada.
} 
posteriores a la siembra, por lo que en la época de su generalización en la región pampeana dio lugar a una reducción notable de los tiempos operativos, de tres horas por hectárea a cuarenta minutos o aún menos (según R. Peretti, citado por Blanco, 2001). Dicha reducción no se tradujo en una disminución equivalente de la demanda de tiempo de trabajo porque en parte ésta se desplazó de las necesidades de labranza a las de manejo de insumos (Blanco, 2001).

Sin duda los factores tecnológicos son importantes, pero existen también razones del tipo que algunos economistas llaman institucionales y que en la literatura han sido mucho menos destacadas. Se trata, simplemente, de que no es posible hacer en el campo todo lo necesario para llevar adelante la producción agropecuaria. El trabajo que ésta requiere está lejos de reducirse a arare cavare: productores y contratistas deben ocuparse también de gestiones financieras, trámites administrativos, pago de impuestos, mantenimiento y reparación de equipos complejos, compra de insumos, venta de productos, consultas con profesionales y otras tareas que se realizan en ciudades y pueblos de cierta importancia. Algunas sólo pueden ejecutarse personalmente, con la particularidad de que las que tal vez sean más apremiantes, como las relacionadas con la atención de obligaciones fiscales y financieras, presentan exigencias de cumplimiento en tiempo y forma que no reparan en las dificultades que pueda tener la población rural para hacerse presente en el lugar, normalmente urbano, donde deben cumplirse. De manera que muchas actividades relacionadas con la producción agropecuaria se facilitan si quien debe ocuparse de ellas tiene residencia urbana.

A la inversa, la cercanía con el lugar de trabajo directo cuando está distante de un centro poblado es la principal ventaja de la residencia rural para un ocupado en el sector agropecuario. La cercanía reduce los costos de transporte y facilita la observación de las condiciones agronómicas y climáticas, así como el control de los procesos biológicos de los que se ocupa la actividad agropecuaria, aumentando las probabilidades de intervención en el momento oportuno; sin embargo, esta ventaja se reduce o desaparece cuando las actividades agropecuarias son estacionales y demandan poco tiempo de trabajo directo por campaña agrícola, como ocurre en la agricultura pampeana contemporánea, en la que las labores se concentran en unas pocas semanas por año y fuera de las cuales sólo se requieren tareas de control bastante ligeras y poco demandantes de tiempo. La ganadería, por el contrario, tiene exigencias de presencia mucho más continua en la explotación.

Considerando exclusivamente las necesidades productivas, la residencia urbana o rural de la población ocupada en el sector agropecuario tiene ventajas y desventajas que dependen del tipo de producción y la 
tecnología en uso, en la medida que afectan las necesidades de presencia de los trabajadores en la explotación, así como de la distancia entre ésta y los centros poblados de cierta importancia. Indudablemente la categoría ocupacional también importa, porque los asalariados no necesariamente tienen a cargo actividades del tipo que empresarios y trabajadores, por cuenta propia, deben realizar en el medio urbano; sin embargo, si sus tareas son estacionales, quienes los emplean pueden preferir contratar trabajadores urbanos temporarios en lugar de tomar empleados permanentes que residan en la misma explotación.

Por otra parte, en la región pampeana la residencia del personal en la explotación agropecuaria no garantiza la cercanía en todo momento del lugar de trabajo directo, debido a la fragmentación parcelaria que ha llegado a un punto tal que la maquinaria agrícola fabricada en Argentina se diseńa especialmente para facilitar los desplazamientos frecuentes por caminos públicos. ${ }^{8}$

En el periodo que va de 2001 a 2002 más de la mitad de las explotaciones agropecuarias que ocupaban $75 \%$ de la superficie estaban compuestas por dos o más parcelas, ${ }^{9}$ y muchas combinaban la propiedad de la tierra con el arrendamiento. La cuarta parte de las explotaciones pampeanas se encontraban en esta situación, ocupando una cantidad desproporcionadamente grande de tierra, ya que abarcaban más de 35\% de la región y tenían una superficie promedio que casi duplicaba a la de aquellas en las cuales la forma de tenencia era propiedad o alquiler exclusivamente. Sin duda esto es, en gran medida, una consecuencia de la división hereditaria de la propiedad y el aumento persistente de la escala mínima de explotación, factores que combinados ponen a los productores o sus descendientes ante la disyuntiva de crecer, casi siempre como contratistas en el mundo de los agronegocios o son orillados a cesar la actividad, convirtiéndose en rentistas cuando son dueños de la tierra (Gras y Hernández, 2009).

De hecho, las facilidades para el arrendamiento, acordado muchas veces de manera informal, posibilitaron un ajuste relativamente suave a los cambios tecnológicos, así como a las consecuencias de los avatares económicos que sufrió Argentina durante las últimas décadas, permitiendo el crecimiento de las explotaciones sin necesidad de destinar recursos a la compra de tierras y habilitando una salida menos traumática para las familias agrarias expulsadas de la actividad productiva.

\footnotetext{
${ }^{8}$ Información obtenida de fabricantes de maquinaria agrícola e ingenieros expertos en el tema durante un trabajo de campo realizado en 2007 por uno de los autores.

${ }^{9}$ Este dato, como todos los que se presentan en adelante sin citar la fuente, es una estimación propia, basada en datos censales de $\operatorname{INDEC}(\mathrm{s} / \mathrm{f} / \mathrm{b} ; \mathrm{s} / \mathrm{f} / \mathrm{c})$.
} 


\section{Población rural y conceptos conexos}

Como no podría ser de otra manera, dado lo expuesto arriba, hay una discusión abierta en América Latina en torno a los conceptos estadísticos de urbano y rural en la que abundan propuestas de modificación de las definiciones oficiales vigentes. Puede decirse que, aún con diferencias en aspectos específicos, existe una fuerte corriente de pensamiento que encuentra acogida en organismos internacionales que actúan en el subcontinente como el Banco Mundial, la Comisión Económica para América Latina y el Caribe de las Naciones Unidas (CEPAL) y el Centro Latinoamericano para el Desarrollo Rural (Rimisp), que proponen sustituir el concepto tradicional de lugar urbano, entendido como aglomeración o concentración de población en un área reducida y edificada, por otro que se refiere a zonas más extensas que pueden combinar áreas edificadas con campo abierto. Este sigue un principio análogo al adoptado por la oCDE, que toma a la densidad dentro de delimitaciones administrativas como criterio básico de distinción en el nivel de las comunidades locales y en el nivel regional, a la proporción de población que vive en comunidades rurales.

Así, autores que adoptan el enfoque del Desarrollo Rural Territorial, algunos de los cuales también se ocupan del ERNA, enfatizan la estrecha relación de las ciudades y pueblos inmersos en el medio rural con las áreas agrícolas circundantes (Echeverri y Rivero, 2002; Rodríguez y Saborío, 2007) y teniendo en vista el problema de la pobreza rural, proponen un concepto ampliado de rural que incluya a los núcleos urbanos con los que las áreas pobres tienen vínculos funcionales, tanto productivos como sociales (Schejtman y Berdegué, 2004).

También, autores vinculados con el Banco Mundial como Chomitz et al. (2005), De Ferranti et al. (2005) sugieren sustituir la dicotomía actual por un gradiente determinado por la combinación de un criterio de alta densidad, como el utilizado por la oCDE, con uno de lejanía de las grandes ciudades, definidas como aquellas de más de 100,000 habitantes. En esta propuesta un elemento decisivo para reconocer la condición urbana de la población es la accesibilidad a las grandes ciudades, medida por el tiempo de transporte.

Más recientemente, en una conferencia electrónica internacional realizada en 2008 por CEPAL-Rimisp (s/f) para discutir la posible modificación de los criterios al respecto, se acordó sobre la necesidad de establecer gradientes que permitan capturar no una, sino una pluralidad de ruralidades, también se llegó a la conclusión de que: "la noción de localidad como aglomeración de personas, núcleo poblacional o asentamiento humano... sería una forma de identificar características propias de lo 
urbano vs lo rural" (CEPAL-Rimisp, s/f). Se recuperaría así el criterio tradicional que tiende a identificar lo urbano en Latinoamérica con la concentración demográfica de tipo puntual.

Buscando alternativas para el concepto de ruralidad utilizado en Argentina, y después de explorar varias posibilidades y sus implicancias cuantitativas, Castro y Reboratti (2008) plantean un criterio que combina tipo de asentamiento (agrupado o disperso), tamańo de la localidad y sector de actividad de la población, para elaborar un gradiente de tipos de territorio según su grado de ruralidad. Éste, en definitiva, resulta definido por la proporción de población que trabaja en el sector agropecuario pero reside en centros poblados, aunque los autores proponen un concepto ampliado de fuerza de trabajo agropecuaria, que incluye a quienes se dedican a actividades que participan en cadenas de valor relacionadas con el sector agropecuario en sentido estricto.

En síntesis, la mayoría de estas propuestas apuntan a una definición multivariada de rural que sea de aplicación general, lo cual no es contradictorio con la posibilidad de utilizar diferentes definiciones para unidades territoriales de distinta jerarquía (Du Plessis et al., 2001) -para el caso de Canadá-, o bien, definir zonas con características específicas dentro de las cuales dicha distinción carezca de relevancia debido a las facilidades para el desplazamiento de las personas en su interior, por ejemplo. Este es el caso de las áreas metropolitanas norteamericanas, que según su definición (us Census Bureau, s/f) pueden albergar a población urbana y rural, pero que en sentido amplio son consideradas urbanas al punto que, por exclusión, la llamada América rural es en rigor no metropolitana (ERS/USDA, 2006).

La relación entre rural y urbano también adquiere un significado diferente en los cinturones periurbanos de las grandes ciudades, tal caso se observa en Francia y otros países desarrollados, en donde las zonas aledañas a la urbe están ocupadas tanto por establecimientos agropecuarios como por viviendas de trabajadores con puestos de trabajo urbanos; zonas que pueden ser vistas como rurales porque la mayor parte de la tierra es utilizada para desarrollar actividades agropecuarias y, como urbanas, porque la mayoría de la población ocupada viaja diariamente a la ciudad por motivos de trabajo (Cavailhès et al., 2004).

Aunque no son captados específicamente en las estadísticas oficiales, es indudable que fenómenos de tipo metropolitano y periurbano se presentan en torno de muchas de las grandes ciudades latinoamericanas, en zonas que son clasificadas como rurales pero que por su proximidad con la urbe están bien provistas de infraestructura, equipamiento y servicios, lo que las hace apropiadas para que radiquen familias que, por lo demás, tiene características urbanas. 


\section{Lo urbano y lo rural en la región pampeana argentina}

De acuerdo con los criterios usuales en Latinoamérica, para las estadísticas argentinas, las categorías urbano y rural no se relacionan con delimitación política o administrativa alguna, sino sólo con el constructo estadístico denominado localidad, con el que se procura sistematizar la noción de punto de aglomeración demográfica o centro poblado. Se trata de un área que limita con una envolvente concentración de edificios conectados entre sí por una red de calles, situada dentro de una jurisdicción de gobierno local. Cuando la zona edificada se extiende sobre varias jurisdicciones se tiene un aglomerado o localidad compuesta (INDEC, 1998). No es necesario que la red de calles figure en los planos catastrales y basta que sea visible en el terreno, por lo que una localidad puede conformarse con un agrupamiento informal de edificios, los cuales no necesariamente tienen que ser viviendas ni muy numerosos, basta con ocho y aun menos, si algunos superan ciertos mínimos de superficie o altura.

La población censada dentro de una localidad se clasifica como urbana cuando alcanza o supera los 2,000 habitantes, y como rural, si el número es menor. La población censada fuera de cualquier localidad se clasifica como rural, sin importar si está cerca o lejos ni si mantiene vínculos funcionales o realiza viajes pendulares diarios. Este criterio se vuelve problemático cuando lo que interesa son los alrededores de las grandes ciudades, porque la población que reside en torno a ellas en áreas que pueden tener características metropolitanas o periurbanas no es identificada ni clasificada por separado, sino simplemente agregada a la población urbana o rural de la unidad territorial de que se trate.

Pero los problemas no se reducen a los señalados: en la zona estudiada en esta investigación, así como en la región pampeana en general, no sólo es arbitrario el umbral de 2,000 habitantes sino que también parecen inadecuadas las propuestas que propugnan la ampliación de la definición de rural a localidades de mayor tamaño con el argumento de que tienen vínculos estrechos con las zonas campestres que la rodean.

En efecto, la estructura urbana y el sistema de transporte se desarrollaron históricamente en función de las necesidades de la colonización, la explotación agropecuaria y la exportación de la producción, por lo que se generó una red de localidades de diferentes tamaños que abarca la totalidad del territorio, de manera que ningún punto está verdaderamente alejado de una ciudad de cierta importancia (ORDP, 1971), y ninguna zona relativamente extensa carece en la actualidad de localidades que superen los 2,000 habitantes, de manera que pueda decirse de ella que es completamente rural porque no cuenta con dichas características. 
Las localidades cuya población se clasifica como rural están intercaladas con otras clasificadas como urbanas y vinculadas con éstas por medio de rutas que están casi siempre pavimentadas y, con frecuencia, dotadas de servicios regulares de transporte público de pasajeros que facilitan viajes de bajo costo. Pero si las localidades no están en general demasiado apartadas entre sí, tampoco están tan próximas como para que la distancia entre todo punto situado en campo abierto y alguna localidad sea insignificante en términos de costo, tiempo y dificultades de desplazamiento. Estas dificultades se presentan principalmente porque las redes viales rurales, necesarias para facilitar la movilidad de la población, están formadas casi exclusivamente por caminos de tierra cuya transitabilidad se ve afectada por las lluvias propias de la región (Aragón, 1998).

Eso significa que la movilidad de la población de ciudades y pueblos depende de diversas circunstancias: en muchos casos el desplazamiento se ve severamente restringido por el clima, lo cual limita las posibilidades de acceder en cualquier momento a bienes y servicios urbanos, o peor aún, problematiza los viajes pendulares que por motivos de trabajo o estudio se realizan diariamente, es decir, la población residente en campo abierto, salvo la pequeña cantidad que se encuentra junto a rutas pavimentadas o muy cerca de los centros poblados de cierta importancia, está expuesta a mayores dificultades de transporte e incertidumbres de origen climático que condicionan su movilidad.

Al mismo tiempo, difícilmente la población encuentra en las cercanías de su lugar de residencia establecimientos que ofrezcan los bienes necesarios para atender los requerimientos de una vida de clase media en materias tan críticas como educación básica y servicios médicos de emergencia y, sin distinción de ingresos, hasta de abastecimiento de alimentos frescos, por lo que los viajes a centros poblados para comprar mercancías, disfrutar de servicios o cumplir obligaciones de diferente tipo resultan imprescindibles. Como consecuencia de ambos hechos la población dispersa experimenta una insuficiente o más dificultosa provisión de bienes públicos y privados en comparación con la población de nivel socioeconómico equivalente, agrupada en los centros poblados no muy distantes donde se concentra la oferta, particularmente de servicios. ${ }^{10}$

Con excepción de los habitantes de localidades muy pequeñas y aisladas que pueden encontrarse en condiciones no muy diferentes de quienes viven en campo abierto, la verdadera disparidad en lo que a

\footnotetext{
${ }^{10}$ Paradójicamente, este hecho abre posibilidades de alojamiento barato para familias de bajos ingresos con empleo urbano, porque los propietarios de viviendas cercanas a los centros poblados que ya no las utilizan (en 2001,37\% de las viviendas de la región pampeana situadas en campo abierto estaban desocupadas), a veces las ceden en comodato a título gratuito para evitar que queden abandonadas y se deterioren o sean ocupadas por intrusos.
} 
condiciones de vida se refiere se da entre población agrupada y dispersa y no entre población urbana y rural, según la clasificación estadística. Esto parece haber sido advertido por el Instituto Provincial de Estadística y Censos (IPEC) de la provincia de Santa Fe, organismo oficial que se aparta de la norma nacional y clasifica como rural exclusivamente a la población que reside fuera de la planta urbana de municipios y comunas ),esto es, fuera de los centros poblados a los que se considera con entidad suficiente como para tener instituciones propias de gobierno local; para ello se requiere que hayan alcanzado una población de 10,000 habitantes para ser municipio y de 500 para considerarse comuna, ${ }^{11}$ aunque en la práctica siguen conservando su condición jurídica aún cuando la población decaiga por debajo de esas cifras.

Este concepto restringido de rural no coincide exactamente con el de población dispersa porque también comprende a los habitantes de las localidades que son demasiado pequeñas para acceder a la categoría de municipio o comuna, que en el sur de Santa Fe son muy pocas y en su mayoría se encuentran en las inmediaciones del Aglomerado Gran Rosario (denominado el aglomerado, en adelante).

En la parte empírica de este análisis se adopta el concepto restringido porque se adapta mejor a las condiciones locales. Adoptar una definición que no tiene en cuenta la magnitud demográfica de municipios y comunas no significa que el atractivo que cada uno encierra en virtud de la gama de bienes que en él se ofrecen sea independiente de su tamaño. Al contrario, por razones que han sido ampliamente estudiadas desde la época de Christaller (Camagni, 2005), la amplitud de aquella gama y, en consecuencia, las ventajas relativas de vivir en un centro poblado cambian según su población. Al menos hasta alcanzar los límites de una ciudad muy grande, el atractivo seguramente aumente cuanto mayor sea la población.

Dentro de la población rural definida de la manera indicada sería de mucho interés distinguir entre aquella que se encuentra en las cercanías inmediatas a los centros poblados de la que está más alejada, pero la división del territorio en radios censales (la unidad mínima de agregación de los datos publicados en los censos de población argentinos) no permite hacerlo para las ciudades pequeńas y los pueblos. En cambio es posible lograr una aproximación razonable para los grandes aglomerados urbanos porque su influencia se extiende sobre áreas suficientemente extensas como para abarcar no sólo radios completos sino delimitaciones territoriales mayores, como los distritos a los que se hacen referencia más adelante.

\footnotetext{
${ }^{11}$ Constitución de la Provincia de Santa Fe y Ley Provincial núm. 2.439, respectivamente.
} 


\section{4. Áreas económicas locales}

Los censos de población realizados en Argentina no permiten identificar las áreas dentro de las cuales la población realiza viajes pendulares diarios por motivos de trabajo, pero el Ministerio de Trabajo, Empleo y Seguridad Social de la Nación (MTESs, 2005) se propuso hacerlo utilizando para ello los registros administrativos del sistema de previsión social. A esos efectos definió al área económica local como una porción de territorio que resulta delimitada por los movimientos diarios pendulares por motivos de trabajo entre una ciudad nodo y su área de influencia.

Habiendo elegido previamente cada nodo, se identificaron ciudades más pequeñas y pueblos para los que resultaban significativos los viajes pendulares diarios, aunque sin fijar un criterio de significación uniforme ni hacerlo explícito en cada caso (Mazorra et al., 2005). Para identificar los lugares vinculados se utilizaron códigos postales, que como regla general no permiten distinguir las zonas edificadas del campo abierto, por lo que en este contexto la expresión ciudades y pueblos debe entenderse en el sentido de localidades con su entorno campestre.

Entre otros aspectos, la validez del estudio está restringida por su cobertura, limitada a los asalariados de empresas privadas registrados en el sistema de seguridad social, que en la época a la que se refiere el estudio representaban alrededor de un tercio de la población ocupada. No obstante, proporciona la mejor aproximación disponible a las zonas en torno a ciudades importantes dentro de las cuales la población se mueve diariamente por motivos de trabajo y de las que, por esta razón, puede decirse que tienen una característica de tipo metropolitano o periurbano, aunque no se conozca la intensidad con que se presenta. El Área Económica Local de Rosario fue una de las reconocidas y se utilizará más adelante en este análisis.

\section{Los empleos no rural y no agrario en la Microrregión Rosario}

\subsection{Delimitación}

Aquí se denomina Microrregión Rosario a la formada por seis departamentos del sur de la provincia de Santa Fe sobre los que la ciudad de Rosario ejerce una influencia directa, con exclusión de cuatro distritos del sudeste que pertenecen a otra área económica local. Se encuentra en el centro-norte de la región pampeana (figura 1) y abarca una superficie de 15,734 kilómetros cuadrados (equivalente a algo más de la mitad de Bélgica). Limita al este con el río Paraná, mientras que en las demás di- 


\section{Figura 1 \\ Microrregión Rosario}
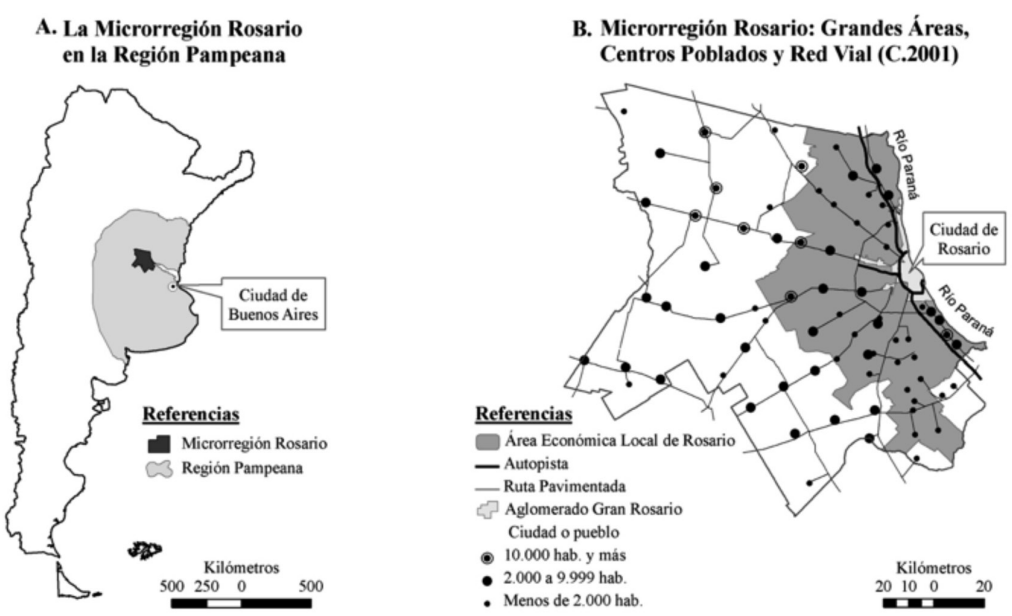

Fuente: Elaboración propia con base de Carlevari y Carlevari (2007), Prosiga (s/f), PEMrR (2005) e $\operatorname{IDESF}(\mathrm{s} / \mathrm{f})$.

recciones las delimitaciones son político-administrativas, sin que se adviertan discontinuidades perceptibles en otros aspectos.

Además del Aglomerado Gran Rosario integrado por la ciudad homónima y un conurbano de 10 localidades, la microrregión contenía en 2001 una red de ocho ciudades pequeñas de entre 10,000 y algo más de 30,000 habitantes y 68 pueblos de menor tamańo, casi todos vinculados con Rosario mediante un sistema radial de autopistas y rutas pavimentadas (figura 2).

La provincia de Santa Fe está dividida en departamentos y éstos en distritos, que son las jurisdicciones territoriales de municipios y comunas, cuyas cabeceras se denominan, respectivamente, ciudades y pueblos en el habla cotidiana local. Además de servir más adelante para la desagregación espacial, la división en distritos fue utilizada aquí para definir la delimitación del Área Económica Local de Rosario, Área de Rosario (para simplificar), adoptándose como tal la envolvente de aquellos distritos que corresponden a las ciudades y pueblos identificados por el MTEss en la investigación antes mencionada, como aquellos para los que resultaban significativos los viajes pendulares diarios por motivos de trabajo centrados en Rosario. 


\subsection{Características económicas}

La región pampeana se corresponde con una llanura fértil de clima templado situada en el centro-este de Argentina. A comienzos del siglo xxi en ella se practicaban, con carácter extensivo, tanto la ganadería a cielo abierto como la agricultura de secano, aunque ésta se concentraba principalmente en su centro-norte. Este rasgo está presente desde hace mucho tiempo y se acentuó durante el último cuarto del siglo xx, cuando la ganadería fue desplazada de las zonas con mayor aptitud agrícola para dar lugar a la expansión del cultivo de soja realizado con vistas a la exportación. Como parte del mismo proceso se desarrolló en el Aglomerado Gran Rosario y sus cercanías un complejo portuario y agroindustrial que se extiende a lo largo de unos 60 kilómetros de costa fluvial y cumple funciones de interfase con la demanda internacional de granos, aceites y harinas proteicas (Castagna et al., 2011).

Desde el punto de vista agropecuario, la Microrregión Rosario posee las características generales del centro-norte de la región pampeana, y a comienzos de siglo en ella se destinaba a la agricultura $90 \%$ de la superficie implantada. La poca actividad ganadera que aún existía estaba relativamente concentrada en la zona norte, donde se encontraba casi la mitad del rodeo bovino en algo más de un tercio de la superficie, si bien éste era el tipo de ganado más abundante, también existía producción porcina. Asimismo se practicaba algo de horticultura comercial, principalmente en los alrededores del aglomerado, aunque como una actividad en franco retroceso frente al avance de la agricultura extensiva por un lado y la urbanización por el otro.

La microrregión también presenta grados considerables de industrialización y desarrollo del sector terciario, con establecimientos pequeńos y medianos distribuidos en localidades de todo tamaño a través del territorio, mientras las grandes plantas manufactureras y la mayoría de los prestadores de servicios modernos se encuentran tanto en zonas urbanas como rurales, junto o cerca del río Paraná y alrededor de un eje vial norte-sur no muy distante de éste (figura 2). La concentración industrial al norte de Rosario comenzó a gestarse alrededor de 1930 y se intensificó después de 1960, contribuyendo a la conformación del conurbano en tanto que la expansión al sur de éste, es más reciente, más dispersa y aún en la actualidad hay puertos y fábricas localizados en zonas no urbanizadas distantes hasta unos 15 kilómetros del aglomerado, lo cual seguramente está vinculado con el patrón de distribución espacial del empleo que se identificará más adelante.

Así, las ciudades pequeñas cumplen funciones de centros de servicios, no sólo para la población radicada en ellas y sus inmediaciones rurales, 
sino también para la de los pueblos más pequeños de las proximidades. Tanto la oferta de servicios educativos como la complejidad de los centros asistenciales y las jerarquías de las oficinas gubernamentales aumentan en función del tamaño de la localidad, habiendo una discontinuidad perceptible entre pueblos y ciudades pequeñas, y entre éstos y la ciudad de Rosario.

\subsection{Población}

En 2001 la población de la Microrregión Rosario, altamente concentrada en el aglomerado, era de 1,500,000 habitantes, de los cuales menos de 50,000 vivían en zonas rurales y 330,000 en ciudades pequeñas y pueblos. La población de estas localidades se dividía aproximadamente en partes iguales entre el Área de Rosario y el resto del territorio. No ocurría lo mismo con la población rural, que casi en sus tres cuartas partes se concentraba en el Área de Rosario, la cual comprende apenas un tercio de la superficie no urbanizada de la microrregión.

Durante el periodo intercensal 1991-2001 el crecimiento demográfico fue muy débil, de apenas la tercera parte del promedio nacional de 13.1\%. A ésta debilidad contribuyeron tanto la caída de la población rural como el estancamiento del aglomerado, cuya ciudad central prácticamente no varió en número de habitantes. La población de los otros centros poblados, en cambio, aumentó en proporción mucho mayor, especialmente dentro del Área de Rosario donde también creció la población rural, en tanto que en el resto de la microrregión se redujo drásticamente (cuadro 1).

Como resultado de estos cambios aumentó ligeramente la participación relativa del área debido a que el crecimiento demográfico en los alrededores del aglomerado sobrecompensó el escaso dinamismo de éste (cuadro 1), tal como se espera de acuerdo con la hipótesis de la descentración concentrada en sentido distributivo.

\subsection{Empleos no agrario y no rural}

Aplicando al término población rural el sentido restringido que le da el organismo estadístico de la provincia de Santa Fe (esto es, población residente fuera de planta urbana de municipios y comunas), en 2001 poco más de $5 \%$ de la población ocupada tenía empleo rural no agrario o agrario no rural. Si bien el porcentaje señalado parece pequeño y más aún si se divide en sus dos componentes, la proporción que alcanza cada uno en relación con el grupo demográfico relevante no es en absoluto despreciable: alrededor de dos tercios de la población rural ocupada y de la po- 


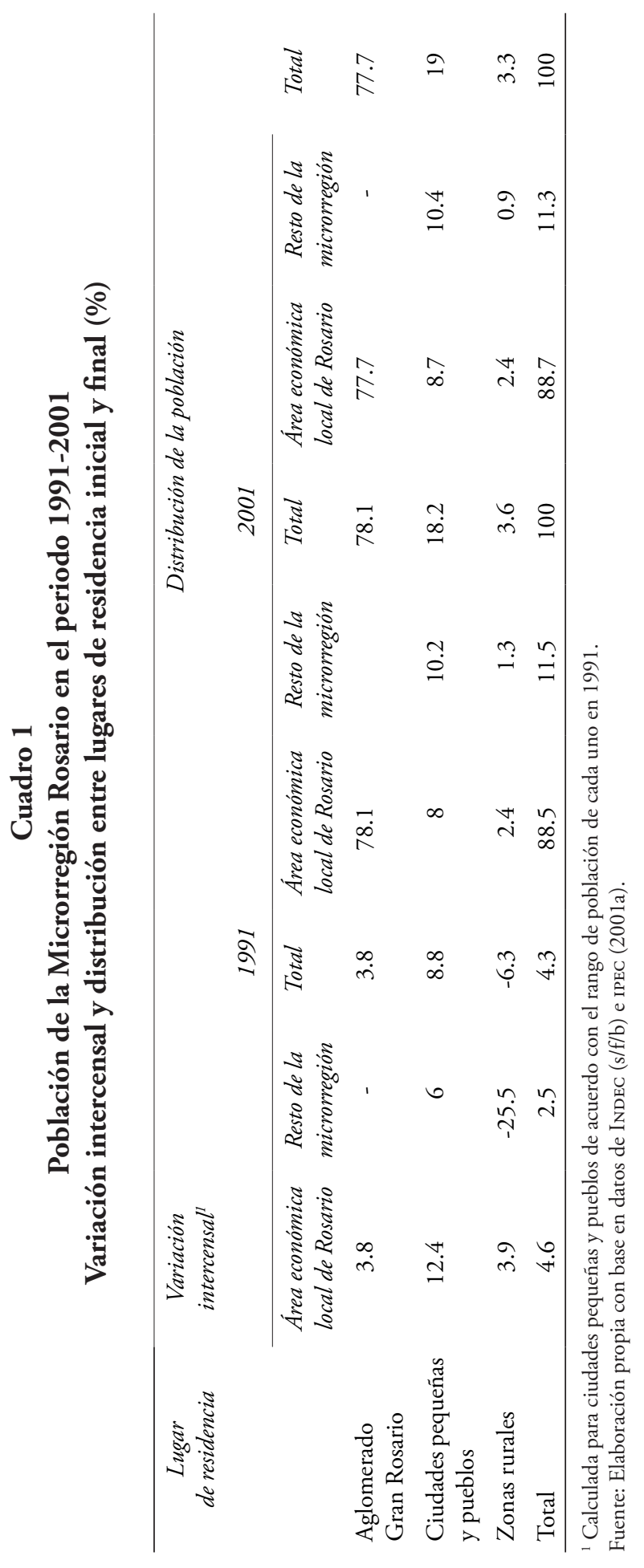


blación con empleo agrario tenía uno de esos empleos. Esas dos poblaciones, respectivamente, se tomarán en adelante como base para calcular la incidencia de cada tipo de empleo analizado que, para simplificar la exposición y por el orden en que fueron presentados, se denominan:

Empleo Tipo I: rural no agrario

Empleo Tipo II: agrario no rural

En términos relativos, la incidencia de ambos aumentó sensiblemente en el periodo intercensal, a pesar de que en cantidades absolutas el empleo Tipo I se mantuvo virtualmente constante y el Tipo II cayó en una cuarta parte (cuadro 2). No obstante, el empleo agrario total se redujo mucho más, en $35 \%$ sin grandes diferencias entre áreas, por lo cual puede decirse que el mismo se desruralizó mientras retrocedía cuantitativamente. Aun así, el empleo agrario ${ }^{12}$ no llegaba a constituir una parte significativa de la ocupación de los centros poblados y en aquellos en que su incidencia era mayor: las comunas con menos de 2,000 habitantes situadas fuera del Área de Rosario no alcanzaban 20\% de la población total ocupada.

Si bien el empleo Tipo II se presenta dentro y fuera del Área de Rosario en porcentajes similares en relación con la población base, no ocurre lo mismo con el empleo Tipo I que alcanza una proporción muy elevada dentro de ésta y apenas supera 30\% fuera de sus límites. Ello se refleja en la distribución espacial: en 2001 82.3\% de la población con este último tipo de empleo se encontraba en aquella área, de manera que estaba aun más concentrada en ella que la población rural en general.

\subsection{Un análisis espacial}

El nivel de agregación adoptado en la sección anterior alcanza para presentar un panorama general de la microrregión, pero la descripción no es completa en la medida en que es posible avanzar en un análisis más detallado utilizando datos agregados a nivel de distrito, susceptibles de ser tratados con métodos estadísticos de análisis espacial. ${ }^{13}$ Los datos analizados son los correspondientes a 2001.

La primera pregunta que se procura responder: ¿existen áreas más pequeñas que las consideradas previamente en las cuales uno u otro de

${ }^{12}$ Por empleo agrario se entiende a la ocupación de la población en Agricultura, Ganadería, Caza y Silvicultura, actividades comprendidas en la Categoría A de la Clasificación de Actividades Económicas para Encuestas Sociodemográficas del Mercosur (INDEC s/f/a), que se corresponde con la Sección A de la cilu Rev. 3 United Nations (un, s/f).

${ }^{13}$ Éste fue implementado utilizando el software libre GeoDa 0.9.5-i, disponible en <http:// geodacenter.asu.edu>. 


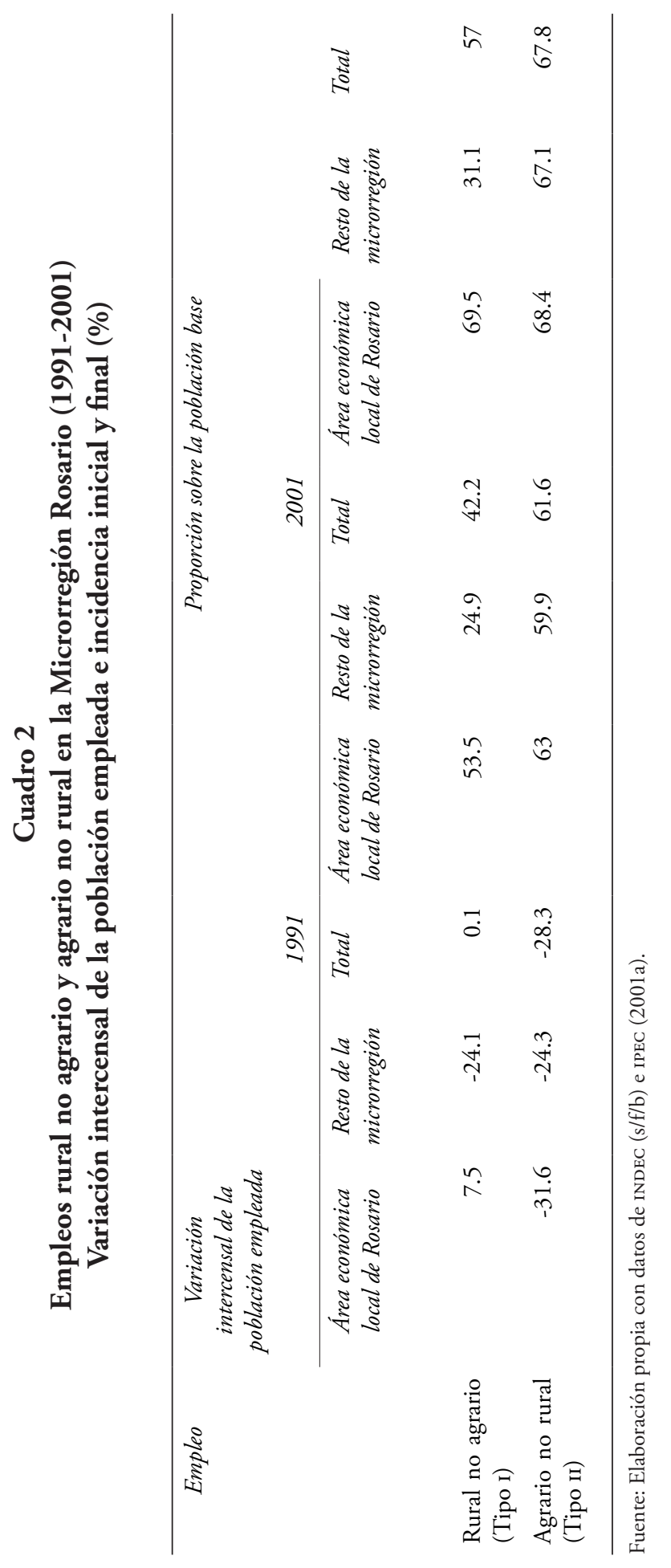


los tipos de empleo estudiados en este análisis está sobre o sub-representado (esto es, si existen patrones de conglomeración espacial dentro de aquellas grandes divisiones o por encima de sus límites)? Para hacerlo se utilizarán Indicadores Locales de Asociación Espacial, LISA por sus siglas en inglés (Anselin, 1994; 2005), que dan una medida del grado de asociación lineal (positiva o negativa) entre el valor de una variable en una localización dada y el promedio espacialmente ponderado de los valores de esa misma variable en sitios vecinos. ${ }^{14}$

Dada la naturaleza del problema entre manos que se refiere a la distribución de las variables en cada distrito y sus alrededores, aquí se considera que son vecinos los distritos contiguos, entendiendo por tales aquellos cuyos límites tienen al menos un lado o un punto en común. En términos técnicos, la adoptada es una definición de vecindad como contigüidad según el criterio de la reina, que admite fronteras en esquina de $1^{\text {er }}$ orden. $^{15}$

Mayores similitudes o disimilitudes entre sitios contiguos que las que se esperan en condiciones de aleatoriedad espacial permiten identificar conglomerados (clusters) espaciales y valores atípicos (outlayers) espaciales. ${ }^{16}$ Cuando los LISA toman valores estadísticamente significativos pueden combinarse de cuatro maneras diferentes correspondientes a valores altos o bajos de la variable en una localización, rodeados de valores también altos o bajos en localizaciones vecinas, o bien, valores altos o bajos rodeados de valores bajos o altos, respectivamente. Combinaciones Alto-Alto y Bajo-Bajo revelan, respectivamente, conglomerados espaciales de valores altos y bajos de una variable mientras que combinaciones Alto-Bajo y viceversa indican la existencia de valores atípicos. Los mapas LISA permi-

${ }^{14}$ Antes de realizar los análisis LISA, y para que éstos tengan sentido, es necesario averiguar si existe autocorrelación espacial, lo que se hace mediante el contraste de $I$ de Moran. En este caso la hipótesis nula de aleatoriedad espacial en la distribución de las variables se rechazó para un alto nivel de significación.

${ }^{15}$ Un criterio alternativo es el de la torre, que sólo exige fronteras compartidas de longitud positiva, esto es, un lado. De hecho, el concepto de vecindad no es unívoco y tiene varios sentidos: contigüidad, cercanía, distancia euclídea o no euclídea, etc., que pueden definirse según diferentes criterios y ser de diversos órdenes o grados. Las relaciones de los valores de una variable en un sitio respecto de los que toma en sitios vecinos se denominan desfasajes espaciales y se representan mediante matrices denominadas matrices de ponderación espacial que tienen tantas filas y columnas como sitios se tomen en consideración. En el caso de contigüidad sus elementos son unos si los sitios están relacionados y ceros si no lo están. Por convención, también son ceros los elementos de la diagonal principal.

${ }^{16}$ Para evaluar la significación de estos indicadores se utiliza el estadístico de prueba conocido como razón de Moran local, simbolizado con $I_{\mathrm{i}}$, donde i representa el sitio al que se refiere el indicador. Éste, que surge de la descomposición del coeficiente de contigüidad $I$ de Moran, se define como: $I_{i}=z_{i} \sum_{j} w_{i j} z_{j}$ donde $\mathrm{z}$ es, para cada localización, el desvío de la variable de interés respecto de su media y $w_{i j}$ son los elementos de la matriz $\mathrm{W}^{\mathrm{s}}$ que representa las desfasajes espaciales entre las localizaciones, estandarizada por filas. La estandarización permite interpretar a los desfasajes espaciales como promedios de los valores vecinos al sitio referido (Anselin, 1994; Anselin et al., 2002). 
ten representar en el espacio geográfico las cuatro posibilidades, quedando en una categoría residual los sitios sin asociación espacial significativa, esto es, todos aquellos para los cuales no se rechaza la hipótesis de aleatoriedad espacial para la variable estudiada.

Para realizar el análisis de la distribución espacial del empleo Tipo II en el nivel de distrito es necesario agrupar algunos de éstos, porque el aglomerado, a pesar de que se extiende sobre varias jurisdicciones de gobierno local, constituye la única unidad socio-demográfica y no tiene sentido dividir a su población urbana según el distrito en que reside para poder compararla con la rural. Por ese motivo se consolidaron todos aquellos cuya zona urbanizada forma parte del mismo. Obviamente, este criterio no es de aplicación para el empleo Tipo I que se distribuye entre zonas rurales solamente, en cuyo caso, mantener la división en distritos permite un estudio más detallado.

Los mapas LISA elaborados con las variables que representan la incidencia de ambos tipos de empleo previamente suavizadas, ${ }^{17}$ revelan que ambas variables tienden a formar conglomerados en lugares que se revelan significativos tan pronto como se les vincula con el patrón de urbanización (figura 2).

El empleo Tipo I tiende a concentrarse en las proximidades del Aglomerado Gran Rosario, evidenciándose una clara oposición entre éstas y los distritos que se adentran en el interior pampeano, con conglomerados de valores altos y bajos hacia el este y el oeste, respectivamente. Debe destacarse que la totalidad del conglomerado de valores bajos se encuentra fuera del Área de Rosario.

En cambio el empleo Tipo II no presenta una relación clara con el aglomerado (al punto que el área formada por los distritos cuyas zonas urbanas lo componen es en sí misma atípica) ni con el Área de Rosario en general. Por el contrario, se insinúa una oposición de orientación surnorte, direcciones en las que se observan los mayores conglomerados de valores altos y bajos, respectivamente.

Como se recordará, hacia el norte se encuentra la zona de mayor incidencia de la ganadería vacuna, por lo que aquella variable podría estar relacionada con la distribución espacial de los diferentes tipos de actividades agropecuarias.

${ }^{17}$ Cuando los LISA son computados para tasas o proporciones, el supuesto de estacionariedad puede ser violado por la inestabilidad intrínseca de las tasas cuando la población base sobre la cual se la calcula varía mucho entre observaciones. Para evitar inferencias espurias el cómputo puede realizarse sobre la variable suavizada de acuerdo al enfoque bayesiano empírico (Empirical Bayes approach). La técnica consiste en calcular un promedio ponderado entre la tasa bruta para cada área y la tasa general de la zona estudiada, con ponderaciones proporcionales a la población de cada uno (Anselin et al., 2004; Anselin, 2005). 


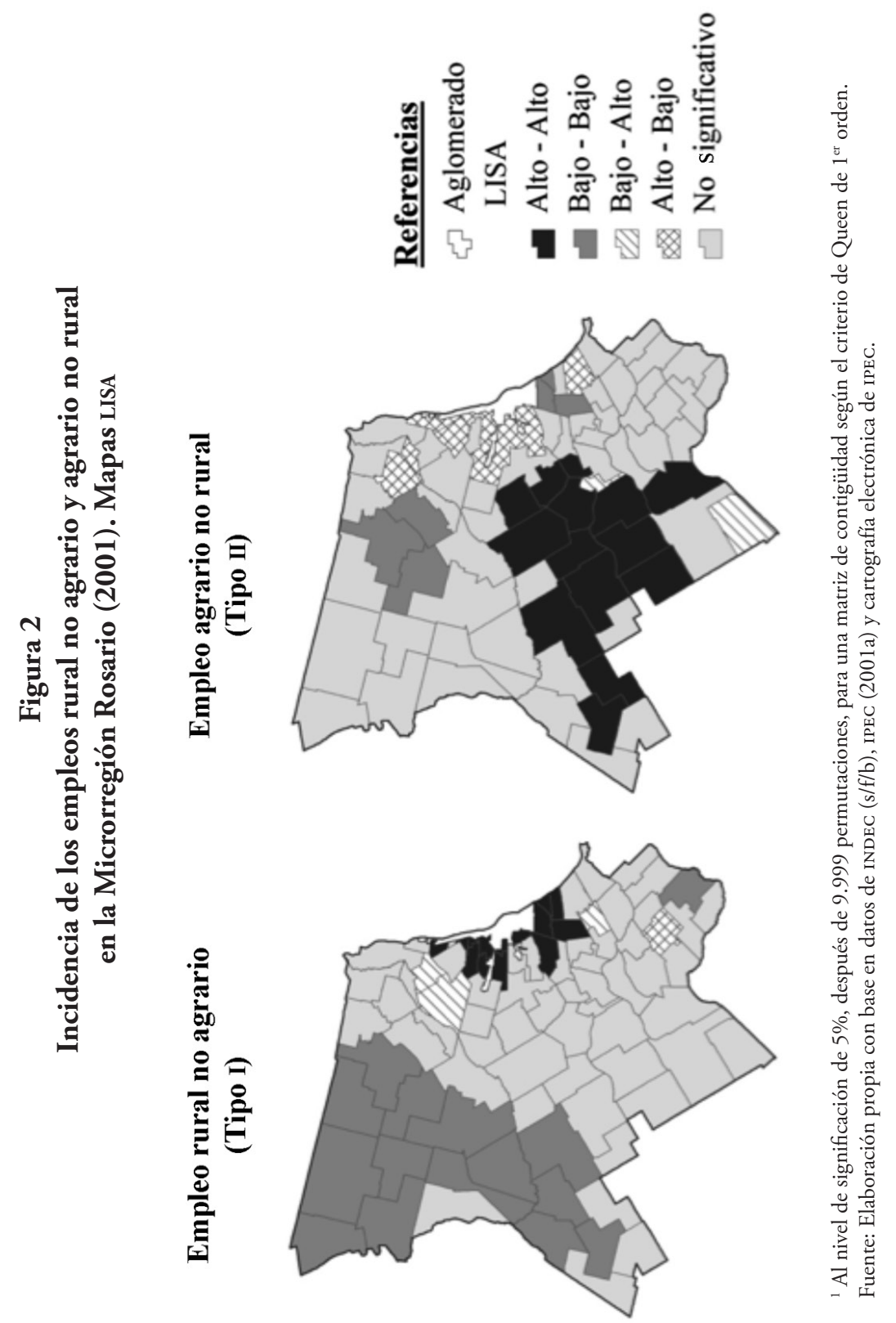


Sin embargo, existe otra relación posible con el patrón de urbanización. Si como es plausible el atractivo de los centros poblados aumenta con su tamaño, el empleo Tipo II debería relacionarse positivamente con el grado de urbanización, que en este caso puede medirse como la cantidad de habitantes de la localidad cabecera de cada distrito en relación con la población total de la jurisdicción, ya que en los pocos casos en que hay más de una localidad en el distrito las que no son sede del municipio o comuna tienen muy pocos habitantes.

De hecho, el empleo Tipo II aparece altamente correlacionado con el grado de urbanización así medido, pero esa correlación puede estar viciada tanto por la influencia de otras variables como por la existencia de efectos espaciales, tales como la autocorrelación espacial que se infiere de la existencia de los conglomerados puesta de relieve por los LISA.

Una forma sencilla y apropiada de evaluar la validez de una relación como la señalada es a través del análisis de la regresión múltiple, utilizando un modelo espacial si están presentes los efectos de esta clase. El procedimiento indicado (Anselin, 2005) prescribe estimar por Mínimos Cuadrados Ordinarios (MCO) un modelo no espacial, y utilizar los residuos que capturan toda la dependencia espacial que pudiera existir (MorenoSerrano y Vayá-Valcarce, 2000), para contrastar primero la hipótesis de que su distribución espacial es aleatoria y después que la especificación del modelo clásico es la correcta frente a especificaciones alternativas de modelos espaciales apropiados para diferentes posibilidades de autocorrelación. ${ }^{18}$ Si en ninguno de los contrastes se rechaza la hipótesis nula (de hecho, si no se la rechaza en el primer contraste no se espera que deba rechazarse en los demás), la estimación por Mco del modelo no espacial es válida en lo que se refiere al problema en consideración (Anselin, 2005).

El modelo econométrico propuesto es un sencillo modelo lineal clásico en el que Incidencia (del empleo Tipo II) toma el papel de variable endógena y los regresores son Urbanización y otras dos variables construidas para captar la influencia de las diferentes formas de ganadería: bovinos por ha y porcinos por ha, definidos como la cantidad de cabezas de cada especie por hectárea de zona rural en cada distrito. El diagnóstico de dependencia espacial realizado con la misma definición de vecindad utilizada para construir los LISA permite retener la estimación por MCO, porque las hipótesis nulas de inexistencia de autocorrelación espacial y de validez de los supuestos del modelo de regresión clásico no se rechazan en ninguno de los contrastes realizados.

\footnotetext{
${ }^{18}$ El programa GeoDa tiene implementado un contraste de Moran adaptado para detectar autocorrelación en los residuos así como contrastes de Multiplicadores de Lagrange sensibles a los dos tipos posibles de autocorrelación, cada uno en versión estándar y robusta (Anselin, 2005).
} 
Los resultados de la regresión (cuadro 3), que explica más de $78 \%$ de la variancia $\left(\mathrm{R}^{2}\right.$ ajustado $\left.=0,7840\right)$, confirman que Incidencia (del empleo agrario no rural) tiene una relación del signo esperado y altamente significativa con Urbanización mientras que los coeficientes que corresponden a las otras dos variables no difieren significativamente de cero con una probabilidad muy alta, lo que descarta que su influencia sea significativa.

\section{Cuadro 3}

\section{Resultados de la estimación del modelo de regresión múltiple por MCO}

\begin{tabular}{lrrrc}
\hline \multicolumn{1}{c}{ Variable } & \multicolumn{4}{c}{ Resumen de la estimación } \\
& Coeficiente & Error estándar & Estadístico $t$ & Probabilidad \\
\hline Constante & $-4,480,804$ & 7.184166 & -6.237054 & 0.0000000 \\
Urbanización & 1.276311 & 0.07925502 & 16.10385 & 0.0000000 \\
Bovinos por ha & -6.29148 & 9.331379 & -0.6742283 & 0.5023561 \\
Porcinos por ha & 1.971373 & 2.63336 & 0.7486151 & 0.4565613 \\
\hline
\end{tabular}

Fuente: Elaboración propia con base en datos de INDEC (s/f/b), IPEC (2001a; 2001b) y cartografía electrónica de IPEC.

Se concluye, entonces, que la incidencia del empleo agrario no rural en cada distrito es explicada en términos econométricos por el grado de urbanización en ese mismo distrito.

En síntesis, es posible sostener que el análisis empírico realizado corrobora las hipótesis específicas expuestas al principio de este análisis, esto es, que en el caso estudiado el empleo rural no agrario (Tipo I) tiende a concentrarse en las proximidades de la gran área urbana de la microrregión, y que la proporción de empleo agrario que en cada distrito es no rural (empleo Tipo II) tiende a ser mayor cuanto más concentrada esté la población del distrito en la localidad cabecera.

\section{Conclusiones}

La Microrregión Rosario tomada en su conjunto parece proporcionar un caso contundente a quien quiera refutar, una vez más, el viejo paradigma que asociaba ruralidad de la población con empleo agrario: en ella, al comenzar el siglo XXI, la mayor parte del empleo rural no era agrario y la mayor parte del empleo agrario no era rural.

No obstante, un análisis más detallado revela que la primera parte de la proposición es válida sólo para los alrededores del Aglomerado Gran Rosario y, en particular, para sus alrededores inmediatos, mientras que en 
las áreas que se alejan del mismo hacia el interior pampeano, el empleo agrario seguía predominando ampliamente entre la población rural. Ello sugiere que en la Microrregión Rosario, tomada en su conjunto, el empleo rural no agrario era en su mayor parte de carácter periurbano o metropolitano más que propiamente rural. De hecho, la mayor parte se encontraba en el Área de Rosario y se concentraba más intensamente en los alrededores inmediatos del aglomerado, en una zona muy bien servida por vías de acceso pavimentadas.

La validez de la segunda parte de la proposición expresada arriba: "la mayor parte del empleo agrario no era rural", es más general en cuanto a su alcance geográfico, pero también subyace a ella un fenómeno vinculado con la urbanización, en un sentido amplio que toma en cuenta a la población residente en toda clase de ciudades y pueblos. En ellos, la incidencia del empleo agrario no rural era mayor cuanto mayor su población en relación con la de sus alrededores inmediatos.

Así que, en un contexto de crecimiento demográfico consistente con la hipótesis de la desconcentración concentrada (interpretada como cambio en la distribución espacial de la población) en una microrregión donde la actividad agropecuaria es muy relevante, las dos formas de empleo consideradas aparecen relacionadas de maneras específicas con el patrón de urbanización: una, en lo que respecta a la consolidación de áreas de tipo periurbano o metropolitano en torno a las grandes ciudades $y$, otra, en lo que se refiere a las ciudades pequeñas y los pueblos que recuperaron, si es que antes habían perdido su atractivo para la población que trabaja en la zonas rurales cercanas.

Un tema que permanece abierto para futuras investigaciones y que los datos disponibles no permiten indagar, es el que se refiere al lugar de residencia de los trabajadores con empleo Tipo I (rural no agrario) de las zonas más alejadas del aglomerado. Cabe formular la hipótesis de que gran parte de ellos reside no muy lejos de las ciudades pequeñas y los pueblos, tal vez en viviendas rurales suficientemente cercanas a éstos como para que los desplazamientos diarios al centro poblado no se vean dificultados.

Por cierto, la Microrregión Rosario y la región pampeana en general tienen peculiaridades que no permiten generalizar, sin más, las conclusiones obtenidas a otras partes de América Latina. No obstante, justamente por tratarse de una zona relativamente desarrollada y con una agricultura avanzada, puede estar anticipándose a lo que ocurrirá en otros lugares ya que es posible que el crecimiento del empleo no agrario de la población rural y la desruralización del empleo agrario sean fenómenos llamados a generalizarse y extenderse, a medida que avance la tecnología agrícola, mejoren los medios de transporte y comunicación y continúen expan- 
diéndose técnicas que aumentan los tiempos muertos de la producción agropecuaria.

Como comentario final puede decirse que los fenómenos analizados ponen de manifiesto el atractivo que la vida urbana representa para la población que, por su lugar de residencia o por su actividad laboral, está expuesta al aislamiento característico de la vida en el campo. Quienes por algún motivo no pueden o no quieren residir en la gran ciudad, donde las posibilidades de trabajo son mayores, tienden a concentrarse en sus alrededores, en zonas con buena accesibilidad. Por otro lado, quienes encuentran ocupación en el sector agropecuario tienden a residir en centros poblados tanto más cuanto mayor es el tamaño relativo de éstos, donde seguramente la calidad de los servicios como aquellos que les permiten desplazarse con facilidad a ciudades mayores crece en función de su tamaño.

Indudablemente, la concentración demográfica en centros poblados hace más patente el desbalance con el campo abierto tanto en términos de densidad como de oportunidades, y hace más difícil de tolerar el aislamiento y las privaciones de las familias dispersas en la zona rural. En este sentido, el patrón de urbanización, en definitiva, define las posibilidades de relación entre residencia y rama de actividad del empleo, en el caso estudiado.

\section{Bibliografía}

Albanesi, Roxana y Graciela Propersi (2006), "Familias rurales y estructura agraria en el sur de Santa Fe, Argentina”, ponencia presentada en el VII Congreso Latinoamericano de Sociología Rural, 20-24 de noviembre, Quito.

Anselin, Luc (1994), "Local indicators of spatial association-LISA", Research Paper 9231, West Virginia University-Regional Research Institute, <http://www.rri.wvu.edu>, 10 de marzo de 2010.

Anselin, Luc, Ibnu Syabri y Oleg Smirnov (2002), "Visualizing multivariate spatial correlation with dynamically linked windows", University of Illinois, Urbana-Champaign, <http://europa.nvc. cs.vt.edu>, 13 de agosto de 2008.

Anselin, Luc, Yong Wook Kim y Ibnu Syabri (2004), "Web-based analytical tools for the exploration of spatial data", Journal of Geographical Systems, 6 (2), Springer, Berlin, pp. 197-218. 
Anselin, Luc (2005), "Exploring spatial data with GeoDa: A workbook", Arizona State University, <http://www.csiss.org>, 10 de marzo de 2010 .

Aragón, Carlos Federico (1998), "La agricultura productiva requiere una infraestructura eficiente que le sirva", en Otto Solbring y Laura Vainesman, Hacia una agricultura productiva y sostenible en la pampa, Harvard University-David Rockefeller Center for Latin American Studies-Consejo Profesional de Ingeniería Agronómica, Buenos Aires, pp. 138-147.

Ashby, Richard (1941), "Town farming in the great plains", Rural Socio$\log y, 6$ (4), Rural Sociological Society-Bringham Young University, Provo, pp. 341-343.

Belcher, John C. (1954), "The nonresident farmer in the new rural society” , Rural Sociology, 19 (2), Rural Sociological Society-Bringham Young University, Provo, pp. 121-136.

Benencia, Roberto y Germán Quaranta (2006), "Los mercados de trabajo agrarios en la Argentina: demanda y oferta en distintos contextos históricos", documento de trabajo núm. 32, Asociación Argentina de Especialistas en Estudios del Trabajo, Buenos Aires, pp. 81-118.

Berdegué, Julio A., Eduardo Ramírez, Thomas Reardon y Germán Escobar (2001), "Rural nonfarm employment and incomes in Chile", World Development, 29 (3), Department of Geography, McGill University, Montreal, pp. 411-425.

Blanco, Mariela (2001), "La agricultura conservacionista y sus efectos sobre la mano de obra rural. La aplicación de siembra directa en el cultivo de cereales y oleaginosas", en Guillermo Neiman (comp.), Trabajo de campo. Producción, tecnología y empleo en el medio rural, ciccus, Buenos Aires, pp. 134-152.

Bollman, Ray D. (2007), "The demographic overlap of agricultural and rural", working paper núm. 8, Statistics Canada, Agriculture and Rural Working Paper Series, <http://dsp-psd.pwgsc.gc.ca>, 20 de noviembre de 2009. 
Bryden, John y Ray D. Bollman (2000), "Rural employment in industrialized countries", Agricultural Economics, 22 (2), International Association of Agricultural Economists, West-Lafayette pp. 185197, <http://www.sciencedirect.com>, 15 de octubre de 2008.

Camagni, Roberto (2005), Economía urbana, Antoni Bosch Editor, Barcelona.

Carlevari, Isidro J. y Ricardo D. Carlevari (2007), La Argentina. Geografía económica y humana, Alfaomega, Buenos Aires.

Castagna, Alicia, José Luis Pellegrini y María Lidia Woelflin (2011), El nuevo sistema agroexportador en el sur de Santa Fe, UNR Editora, Rosario.

Castro, Hortensia y Carlos Reboratti (2008), "Revisión del concepto de ruralidad en Argentina y alternativas posibles para su redefinición", Serie Estudios e Investigaciones, núm. 15, Secretaría de Agricultura, Ganadería, Pesca y Alimentos-Proinder, Buenos Aires, pp. 1-102.

Cavailhès, Jean, Dominique Peeters, Evangelos Sekeris y Jacques-Francois Thisse (2004), "The periurban city: why to live between the suburbs and the countryside", Regional Science and Urban Economics, 34 (6), Elsevier, Amsterdam, pp. 681-703.

CEPAl (Comisión Económica para América Latina y el Caribe) (2003), "Empleo e ingreso en las actividades rurales no agropecuarias de centroamérica y México", Naciones Unidas-Comisión Económica para América Latina y el Caribe, <http://www.cepal.org>, 11 de julio de 2008.

CEPAL-Celade (Comisión Económica para América Latina y el CaribeCentro Latinoamericano y Caribeño de Demografía) (2005), "América Latina: urbanización y evolución de la población urbana, 1950-2000”, Boletín Demográfico, 75, Celade-Naciones Unidas, Santiago de Chile, <www.eclac.org>, 14 de noviembre de 2009.

CEPAL-Rimisp (Comisión Económica para América Latina y el CaribeCentro Latinoamericano para el Desarrollo Rural) (s/f), "Síntesis final de la conferencia electrónica: pertinencia y consecuencias de modificar los criterios para diferenciar lo urbano de lo rural para 
fines de análisis y diseño de política”, 17 abril a 2 de mayo de 2008, (conferencia electrónica en línea), <http://www.rimisp. org>, 14 de septiembre de 2009.

Cloquell, Silvia (coord.) (2007), Familias rurales. El fin de una historia en el inicio de una nueva agricultura, Homo Sapiens, Rosario.

Constitución de la Provincia de Santa Fe (1962), <http://www.santa-fe. gov.ar>, 15 de junio de 2010.

Craviotti, Clara (1999), "Pluriactividad: su incorporación en los enfoques y en las políticas del desarrollo rural", documento de trabajo núm. 17, Asociación Argentina de Especialistas en Estudios del Trabajo, Buenos Aires, pp. 95-110.

Craviotti, Clara y Alejandro Gerardi (2002), "Implicancias del empleo rural no agropecuario en los hogares rurales de Mendoza, Río Negro y Santa Fe", Serie Estudios e Investigaciones, núm. 3, Secretaría de Agricultura, Ganadería, Pesca y Alimentos-Proinder, Buenos Aires, pp. 1-55.

Champion, Tony (2009), "Urban-rural differences in commuting in England: A challenge to the rural sustainability agenda?", Planning, Practice \& Research, 24 (2), Routledge, pp. 161-183, <http:// rsa.informaworld.com>, 5 de mayo de 2010.

Chomitz, Kenneth, Piet Buys y Thomas Timothy (2005), "Rural-urban gradient in Latin America and the Caribbean", World Bank Policy Research, Working Paper 3634, World Bank, Washington, DC, pp. 1-35.

De Ferranti, David, Guillermo E. Perry y Daniel Lederman (2005), "Beyond the city. The rural contribution to development", World Bank Latin American and Caribbean Studies, World Bank, Washington, DC, pp.1-28.

Dirven, Martine (2004), "El empleo rural no agrícola y la diversidad rural en América Latina”, Revista de la CEPAL, 83, CEPAL, Santiago de Chile, pp. 49-69.

Dirven, Martine (2006), "Small farms in Latin America: Quo vadis? Position paper for a (dis)passionate discussion”, Seminario Inter- 
nacional Desafíos para Enfrentar el Presente y Futuro de la Agricultura Familiar Campesina, 3-4 de octubre, Santiago de Chile.

Du Plessis, Valerie, Roland Beshiri y Ray D. Bollman (2001), "Definitions of rural", Rural and small town Canada analysis bulletin, 3 (3), Statistics Canada, Ottawa, pp.1-17.

Echeverri, Rafael y María Pilar Rivero (2002), Nueva ruralidad. Visión del territorio en América Latina y el Caribe, IICA, Panamá.

ERS-USDA (Economic Research Service-United States Department of Agriculture) (2006), "Measuring rurality", ERS-USDA Briefing Rooms, <http://www.ers.usda.gov>, 11 de julio de 2010.

Ferreira, Francisco H. G. y Peter Lanjouw (2001), "Rural nonfarm activities and poverty in the Brazilian northeast", World Development, 29 (3), Elsevier Science, Great Britain, pp. 509-528.

Gallo, Ezequiel (2004), La pampa gringa, Edhasa, Buenos Aires.

Gorenstein, Silvia, Martín Napal y Mariana Olea (2007), “Territorios agrarios y realidades rururbanas. Reflexiones sobre el desarrollo rural a partir del caso pampeano bonaerense", Revista EURE, XXXIII (100), Instituto de Estudios Urbanos Regionales, Pontificia Universidad Católica, Santiago de Chile, pp. 91-113.

Gras, Carla (2004), "Pluriactividad en el campo argentino: el caso de los productores del sur santafecino", Cuadernos de Desarrollo Rural, núm. 51, Pontificia Universidad Javeriana, Bogotá, pp. 91-114.

Gras, Carla y Valeria Hernández (2009), "Reconfiguraciones sociales frente a las transformaciones de los 90: desplazados, chacareros y empresarios en el nuevo paisaje rural argentino", en Carla Gras y Valeria Hernández (coords.), La Argentina rural: de la agricultura familiar a los agronegocios, Biblos, Buenos Aires, pp. 89-116.

Gras, Carla (2013), "Expansión agrícola y agricultura empresarial: el caso Argentino", Revista de Ciencias Sociales, núm. 32, pp. 73-92, $<$ www.fcs.edu.uy/archivos/Art\%C3\%ADculo\%20Gras\%20 RCCSS\%2032.pdf>, 3 de febrero de 2014. 
Harris, Spencer, Alessandro Alasia y Ray Bollman (2008), "Rural commuting: its relevance to rural and urban labor markets", Rural and small town Canada analysis bulletin, 7 (6), Statistics Canada, Ottawa, pp. 1-23.

Hartwig, Rolf y Lochner Marais (2005), "Farm-worker housing in South Africa: an evaluation of an off-farm housing project", Housing Studies, 20 (6), Routledge, London, pp. 931-948.

INDEC (Instituto Nacional de Estadística y Censos) (1998), "El concepto de localidad: definición, estudios de casos y fundamentos teóricometodológicos", Censo Nacional de Población, Hogares y Vivienda 1991, Serie D, núm. 4, Buenos Aires.

INDEC (Instituto Nacional de Estadística y Censos) (2001), "Aspectos metodológicos", Censo Nacional de Población, Hogares y Vivienda 2001, Instituto Nacional de Estadística y Censos, Buenos Aires, <http://www.indec.gov.ar>, 20 de agosto de 2009.

INDEC (Instituto Nacional de Estadística y Censos) (s/f/a), "Clasificación de actividades económicas para encuestas sociodemográficas del Mercosur (caes Mercosur)", Censo Nacional de Población, Hogares y Vivienda, Apéndice metodológico, <http://www.indec. gov.ar>, 12 de febrero de 2010.

INDEC (Instituto Nacional de Estadística y Censos) (s/f/b), Censo Nacional de Población, Hogares y Vivienda 2001, <http://www.indec. gov.ar>, 20 de noviembre 2009.

INDEC (Instituto Nacional de Estadística y Censos) (s/f/c), Censo Nacional Agropecuario 2002, <http://www.indec.gov.ar>, 12 de agosto de 2010.

IDESF (Infraestructura de Datos Espaciales de Santa Fe) (s/f), Transporte, CD-Rom.

IPEC (Instituto Provincial de Estadística y Censos) (2001a), Censo Nacional de Población, Hogares y Vivienda 2001, Provincia de Santa Fe. Distritos, localidades y parajes, Gobierno de Santa Fe, CD-Rom. 
IPEC (Instituto Provincial de Estadística y Censos) (2001b), Encuesta Ganadera 2001, Provincia de Santa Fe, <http://www.santafe.gov. ar>, 12 de septiembre de 2010.

Jenkins, Warder B. y Hilton E. Robison (1937), "Part-time farming in the United State, special study, U.s. census of agriculture: 1935”, U.s. Departament of Commerce, Bureau of the Census, Washington, DC, <http://books.google.com>, 7 de diciembre de 2011.

Klein, Emilio (1992), "El empleo rural no agrícola en América Latina”, documento de trabajo núm. 364, Organización Internacional de Trabajo-Programa de Empleo para América Latina y el Caribe, Santiago de Chile.

Köbrich, Claus y Martine Dirven (2007), "Características del empleo rural no agrícola en América Latina con énfasis en los servicios”, Revista de la CEPAL, Naciones Unidas-CEPAL, 174, Santiago de Chile, pp. 1-84.

Kollmorgen, Walter M. y George F. Jenks (1958), "Sidewalk farming in Toole County, Montana, and Traill County, North Dakota", Annals of the Association of American Geographers, 48 (1), Taylor \& Francis, Abingdon, pp. 209-231.

Lagos-Escobar, Ricardo (2008), "Un nuevo trato para América Latina Rural”, documento de trabajo núm. 10, Rimisp, Santiago de Chile.

Leveau, Carlos (2009), “Contraurbanización en Argentina? Una aproximación a varias escalas con base en datos censales del periodo 1991-2001", Investigaciones Geográficas. Boletín del Instituto de Geografía, núm. 69, Universidad Nacional Autónoma de México, pp. 85-95.

Ley 22.248 de Trabajo Agrario (1980), <http://infoleg.mecon.gov.ar>, 15 de junio de 2010.

Ley Orgánica 2.439 de Comunas de la Provincia de Santa Fe (1985), Texto ordenado de acuerdo al Decreto $N^{\circ} 66 / 85$ y su modificatorio Decreto $\mathrm{N}^{\circ}$ 823/86, <https://tribunalelectoral.santafe.gov. ar>, 15 de junio de 2010 . 
Lier, John (1971), "Farm mechanization in Saskatchewan”, Tijdschrift voor economische en sociale geografie, 62 (3), The Royal Dach Dutch, Geographical Society (Knag), Utrecht, pp. 180-189.

Lindenboim, Javier y Damián Kennedy (2003), “Continuidad y cambio en la dinámica demográfica de Argentina”, ponencia presentada en las VII Jornadas Nacionales de Estudios de Población, 6-8 de noviembre, AEPA, Tafí del Valle.

Lindenboim, Javier y Damián Kennedy (2004), “Dinámica urbana argentina 1960-2001. Reconstrucción y análisis de la información necesaria”, documento de trabajo núm. 3, IIE-CEPED-Universidad de Buenos Aires, Buenos Aires, pp. 1-58.

Lódola Agustín, Karina Angeletti y Román Fossati (coords.) (2005), "Maquinaria agrícola, estructura agraria y demandantes", Cuadernos de Economía, 72, Ministerio de Economía del Gobierno de la Provincia de Buenos Aires, La Plata, pp. 1-109.

Matjasevic, María Teresa y Alexander Ruiz-Silva (2013), "La construcción social de lo rural", Revista Latinoamericana de Metodología de la Investigación Social, 5 (3), Estudios Sociológicos Editora, Buenos Aires, pp. 24-41. <http://relmis.com.ar/ojs/index.php/relmis/ article/view/60/51>, 3 de febrero de 2014 .

Mazorra, Ximena, Agustín Filippo y Diego Schleser (2005), “Áreas económicas locales y mercado de trabajo en Argentina: estudio de tres casos", Revista de la CEPAL, 157, Naciones Unidas-CEPAL, Santiago de Chile, pp. 1-57.

Moreno-Serrano, Rosina y Esther Vayá-Valcarce (2000), Técnicas econométricas para el tratamiento de datos espaciales. La econometría especial, Universitat de Barcelona, Barcelona.

Mishra, Ashok, Hisham S. El-Osta, Mitchell J. Morehart, James D. Johnson y Jeffrey W. Hopkins (2002), "Income, wealth, and the economic well-being of farm households", Agricultural Economic Report, núm. 812, Resource Economics Division, Economic Research Service-United States Department of Agriculture, Washington, DC, pp. 1-73. 
MTEss (Ministerio de Trabajo, Empleo y Seguridad Social) (2005), "Diversidad productiva en las áreas económicas locales de la región pampeana", Trabajo, ocupación y empleo. Relaciones laborales, territorios y grupos particulares de actividad, 3, MTEss, Buenos Aires, pp. 79-103.

Murmis, Miguel y Silvio Feldman (2006), "Pluriactividad en los pueblos rurales: examen de un pueblo pampeano", en Guillermo Neiman y Clara Craviotti (comps.), Entre el campo y la ciudad. Desafíos y estrategias de la pluriactividad en el agro, ciccus, Buenos Aires, pp. 15-47.

Neiman, Guillermo y Silvia Bardomás (2001), "Continuidad y cambio en la ocupación agropecuaria y rural de la Argentina”, en Guillermo Neiman (comp.), Trabajo de campo. Producción, tecnología y empleo en el medio rural, ciccus, Buenos Aires, pp.12-30.

Neiman, Guillermo, Silvia Bardomás y Matías Berger (2006), "Entre el campo y la ciudad: la pluriactividad en el partido de Cańuelas", en Guillermo Neiman y Clara Craviotti (comps.), Entre el campo y la ciudad. Desafios y estrategias de la pluriactividad en el agro, ciccus, Buenos Aires, pp. 69-88.

(ORDP) Oficina Regional de Desarrollo Pampeana (1971), Región pampeana: poblamiento y urbanización, Presidencia de la Nación-Secretaría de Planeamiento y Acción de Gobierno-Subsecretaría del Conade, Buenos Aires.

Pizzoli, Edoardo y Xiaoning Gong (2007), "How to best classify rural and urban?", ponencia presentada en la Fourth International Conference on Agriculture Statistics, 22-24 de octubre, Beijing.

Pellegrini, José Luis (2008), "La localización del empleo rural no agrícola. Un análisis espacial intraregional”, ponencia presentada en la XLIII Reunión Anual de la Asociación Argentina de Economía Política, Universidad Nacional de Córdoba, 19-21 de noviembre, Córdoba.

(PEMRR) Plan Estratégico Metropolitano Región Rosario (2005), "Plan circunvalar", Infopem, 1(1), Municipalidad de Rosario, Rosario, pp. 4-7. 
Prosiga (Proyecto Sistema de Información Geográfica Nacional de la República Argentina) (s/f), Visor de Mapas, <http://www.sig.gov. ar>, 10 de agosto de 2010 .

Raposo, Isabel y José Pellegrini (2008), "Nueva agricultura y despoblamiento del campo. Trasformaciones del ambiente rural en la región Rosario, Argentina", ponencia presentada en VII Bienal do Colóquio de Transformaçóes Territoriais do Comitê Acadêmico de Desenvolvimento Regional da Associação das Universidades do Grupo de Montevideo, 10-13 de setiembre, Curitiba, CD-Rom.

Reardon, Thomas, Julio Berdegué, Christopher B. Barrett y Kostas Stamoulis (2006), "Household income diversification into rural nonfarm activities", en Steven Haggblade, Peter Hazell and Thomas Reardon (eds.), Transforming the Rural Nonfarm Economy, John Hopkins University Press, Baltimore, pp. 1-33.

Rodríguez, Adrián y Milagro Saborío (2007), "Algunas consideraciones conceptuales y metodológicas sobre la definición y medición de lo rural”, en Adrián Rodríguez y Milagro Saborío (eds.), Lo rural es diverso: evidencia para el caso de Costa Rica, IICA, San José de Costa Rica, pp. 1-23.

Rodríguez-Vignoli, Jorge (2002), "Distribución territorial de la población de América Latina y el Caribe: tendencias, interpretaciones y desafíos para las políticas públicas", Revista de la CEPAL, 32, Celade-CEPAL, Santiago de Chile, pp. 1-85.

Rodríguez-Vignoli, Jorge (2008), "Distribución espacial, migración interna y desarrollo en América Latina y el Caribe", Revista de la CEPAL, 96, Santiago de Chile, pp. 135-155.

Schejtman, Alexander y Julio Berdegué (2004), "Desarrollo territorial rural", Debates y Temas Rurales, 1, Rimisp, Santiago de Chile, pp.1-53.

Schindegger, Friedrich y Cornelia Krajasits (1997), "Commuting: Its importance for rural employment analysis", en Ray Bollman y John Bryden (eds.), Rural employment: An international perspective, САВ International, Wallingford, pp. 164-176. 
Streeten, Paul (ed.) (2001), World Development, 29 (3), Department of Geography, McGill University, Montreal.

(UN) United Nations (s/f), "Estructura detallada y notas explicativas. CIIU Rev. 3”, United Nations Statistics División, <http://unstats. un.org/unsd>, 20 de febrero de 2010.

Urcola, Marcos (2013), "Estrategias socio-productivas y agricultura familiar: las nuevas tecnologías y sus implicancias en las relaciones familiares y productivas en una localidad del sur santafesino”, Mundo Agrario, 13 (26), Universidad Nacional de la Plata, <http://www.mundoagrario.unlp.edu.ar/issue/view/92/> 3 de febrero de 2014.

us Census Bureau (s/f), "Metropolitan and micropolitan statistical areas", Question \& Answer Center, <https://ask.census.gov>, 26 de agosto de 2010 .

Weller, Jurgen (1997), "Empleo rural no agropecuario en el istmo centroamericano", Revista de la CEPAL, 62, Naciones Unidas-CEPAL, Santiago de Chile, pp. 75-90.

Williams, Michael (1970), "Town-farming in the Mallee lands of South Australia and Victoria", Australian Geographical Studies, 8 (2), Institute of Australian Geographer, Sidney, pp.173-191.

Recibido: 20 de abril de 2011. Reenviado: 14 de enero de 2012. Aceptado: 19 de marzo de 2012.

José Luis Pellegrini. Doctor en economía por la Universidad Nacional de Rosario, Argentina y magíster en ciencia política y sociología por la Facultad Latinoamericana de Ciencias Sociales, sede Argentina. Actualmente es profesor titular ordinario de Economía de Empresas, docenteinvestigador en el Instituto de Investigaciones Económicas y secretario de Ciencia y Tecnología de Facultad de Ciencias Económicas y Estadística, Universidad Nacional de Rosario. Tiene categoría i en el Programa de Incentivos a los Docentes-Investigadores de Argentina. Sus investigaciones se centran en la economía regional (urbana y rural) con énfasis en aspectos organizacionales, espaciales y laborales. Entre sus publicaciones recientes se cuentan, en coautoría: El nuevo sistema Agroexportador en el 
sur de Santa Fe, unR Editora, Rosario (2011); en coautoría, "Conocimientos, relaciones y creación de valor en la industria argentina de sembradoras para siembra directa", IJIE, Iberoamerican Journal of Industrial Engineering, 4 (7), Universidade Federal de Santa Catarina, Florianópolis, pp. 48-67 (2012); en coautoría, "Aprendizaje organizacional en una agroindustria exitosa: de la intuición a la institucionalización", Análisis organizacional. Revista de Ciencias Sociales, Facultad de Ciencias Económicas de la Universidad de Buenos Aires, Buenos Aires (de próxima aparición).

Isabel María Raposo. Magíster en planificación urbana y regional por la Universidad de Buenos Aires, Argentina. Actualmente es profesora investigadora del Instituto de Investigaciones Económicas con extensión a las cátedras de Economía Regional y Urbana, y Economía Industrial de la Facultad de Ciencias Económicas y Estadística, Universidad Nacional de Rosario, Argentina. Su actual línea de investigación se relaciona con estudios vinculados con la economía regional y urbana, en temas relativos al desarrollo territorial y las infraestructuras y servicios. Entre sus publicaciones recientes se pueden mencionar: "Reestructuración ferroviaria en Argentina y cambios en el territorio. Una verificación en la Región Metropolitana Rosario" Revista Transporte y Territorio, 1, Universidad de Buenos Aires, Buenos Aires, pp. 25-56 (2009); en coautoría, "Evolución de los asentamientos irregulares en Rosario. Análisis de una problemática compleja de revertir en el ámbito local", Scripta Nova Revista Electrónica de Geografía y Ciencias Sociales, XIV, 31 (81) Universidad de Barcelona, s.p.i. (2010); en coautoría, "Experiencias vinculadas al desarrollo local. El caso de Rosario y su espacio metropolitano", en Rocío Rosales Ortega (coord.), Desarrollo Local. Teoría y práctica socio territoriales, Universidad Autónoma Metropolitana, unidad Iztapalapa-Miguel Ángel Porrúa, México, pp. 375-409 (2007). 